\title{
IL-15 and a Two-Step Maturation Process Improve Bone Marrow-Derived Dendritic Cell Cancer Vaccine
}

\author{
Ananda Mookerjee ${ }^{1, t, \ddagger}$, Michele Graciotti ${ }^{2,3, \ddagger}$ and Lana E. Kandalaft ${ }^{1,2,3, *}$ \\ 1 Ovarian Cancer Research Center, University of Pennsylvania, Philadelphia, PA 19104, USA; \\ mookerjeeananda@gmail.com or ananda.mookerjee@mssm.edu \\ 2 Ludwig Cancer Research Center, University of Lausanne, Épalinges 1066, Switzerland; \\ michele.graciotti@chuv.ch \\ 3 Department of Oncology, University Hospital of Lausanne, Lausanne 1011, Switzerland \\ * Correspondence: lana.kandalaft@chuv.ch; Tel.: +41-021-314-6295 \\ + Currently at: Cardiovascular Research Center, Icahn School of Medicine, Mount Sinai, New York, \\ NY 10029, USA. \\ $\ddagger$ These authors contributed equally to this work.
}

Received: 27 November 2018; Accepted: 21 December 2018; Published: 4 January 2019 updates

\begin{abstract}
In the last 20 years, dendritic cells (DCs) have been largely used as a platform for therapeutic vaccination in cancer patients. However, despite its proven safety and ability to induce cancer specific immune responses, the clinical benefits of DC-based immunotherapy are currently very limited. Thus, novel approaches are still needed to boost its efficacy. Our group recently showed that squaric acid treatment of antigens is an important adjuvant that can increase vaccine-induced downstream immune responses and therapeutic outcomes. Here we further improved this dendritic cell vaccine formulation by developing a new method for differentiating and maturing DCs from their bone marrow precursors. Our data demonstrate that bone marrow-derived DCs differentiated with GM-CSF and IL-15 and matured with a maturation cocktail in two steps present a more mature and immunogenic phenotype, compared to standard DC preparations. Further suppression of the prostaglandin $E_{2}$ pathway achieved even more immunogenic DC phenotypes. This vaccine was more potent at delaying tumor growth, improved animal survival and induced a more immunogenic and Th1-skewed $\mathrm{T}$ cell response in an ovarian cancer mouse model. These promising results support future efforts for the clinical translation of this approach.
\end{abstract}

Keywords: cancer vaccine; dendritic cell; ovarian cancer; interleukin 15; squaric acid

\section{Introduction}

Ovarian cancer is one of the most severe gynecologic cancers and has a very high mortality rate. Over 230,000 women are diagnosed with ovarian cancer worldwide each year, and about 140,000 women die from the disease [1]. Unfortunately, $85 \%$ of all ovarian cancer cases are detected only at a late-stage, with a 5-year survival rate of 39\% [1].

Previous evidence demonstrated that despite the relatively low mutational burden in ovarian carcinoma compared to other cancer types [2,3], tumor infiltrating $\mathrm{T}$ lymphocytes naturally occur in $>50 \%$ of ovarian cancer patients, a feature that well correlates with improved clinical outcomes [4]. Furthermore, $\mathrm{T}$ cells isolated from ovarian cancer patients are able to recognize tumor-associated antigens (TAAs) and exhibit tumor-specific cytotoxic activity in vitro [5]. Based on this collective evidence, subsequent clinical studies employed dendritic cell (DC) based cancer vaccines in an attempt to stimulate and sustain a tumor specific $\mathrm{T}$ cell response. These studies [6] (and others for other types of cancer) [7] importantly demonstrated the clinical safety and feasibility of DC based vaccines. 
However, despite the crucial role of DCs in stimulating and orchestrating both innate and adoptive immune responses [8], the objective response rates of clinical studies with DC cancer vaccines rarely exceeded $15 \%[9,10]$. Hence, it is generally believed that we have not yet harnessed the true potential of DC-based anti-cancer vaccines and novel strategies should be developed to improve current therapeutic outcomes [11].

Two aspects of DC immunobiology are particularly crucial in designing a DC vaccine: the antigen source and the differentiation and maturation stimuli engaged. Our group previously focused on optimizing whole tumor cell lysate (WTL) preparation identifying in particular $\mathrm{HOCl}[12,13]$ and squaric acid [14] as two potent treatments able to increase the immunogenicity of the WTL antigen source. In this study we focused instead on the optimization of the differentiation and maturation stimuli applied respectively to DC precursors and immature DCs in order to reach their fully immunogenic potential. The most widely accepted protocol to prepare DCs for clinical cancer vaccination involves the differentiation of DCs from their isolated precursors (peripheral blood monocytes in humans or bone marrow cells in mice) in the presence of granulocyte-macrophage colony-stimulating factor (GM-CSF) and interleukin-4 (IL-4) [15]. In more recent years, an alternative type of DCs called "IL-15 DCs" differentiated in the presence of GM-CSF and interleukin-15 (IL-15) has also emerged as an efficient and potentially more immunogenic vaccine for therapeutic applications [16-18]. Instead, for maturation, a much wider variety of cytokine cocktails have been used by different groups [10]. In particular, a cocktail mixture containing tumor necrosis factor- $\alpha$ (TNF- $\alpha$ ), interleukin-1 $\beta$ (IL-1 $\beta$ ), interleukin-6 (IL-6), and prostaglandin $E_{2}$ (PGE2), is currently considered the gold standard for DC maturation and had been largely used in the context of anti-cancer therapeutic vaccines $[19,20]$. This mix is able to efficiently induce expression of common DC surface maturation markers, uniform DC maturation, as well as high levels of $\mathrm{T}$ cell proliferation and priming [19]. However, DCs matured with this mixture failed to produce significant levels of interleukin-12 (IL-12) a crucial signal for $\mathrm{T}$ cell activation and Th1 differentiation [21]. On the other hand, our group previously demonstrated that DC maturation in the presence of lipopolysaccharide (LPS) and interferon- $\gamma$ (IFN- $\gamma$ ) led to high levels of IL-12 production [22,23], an approach that was subsequently translated also into a phase I clinical trial with promising results $[12,13,24]$. In addition to this, other groups also successfully matured DCs in the presence of CD40 ligand and IFN- $\gamma$ [25], or toll-like receptor ligands [26].

Based on this collective evidence, in this study, we characterize and compare the efficacy of DCs differentiated with either IL-4 or IL-15 and a cocktail of differentiation and maturation stimuli in a mouse model of metastatic ovarian cancer in an attempt to improve currently available DC vaccine formulations (Figure 1). Our results demonstrate that DCs differentiated with GM-CSF and IL-15 and matured in the presence of anti-CD40, anti-PGE2, anti-PGE2 receptor (EP2), anti-IL-10 receptor antibodies and CpG oligonucleotides (CPG) (in addition to the canonical LPS and IFN $\gamma$ ) exhibited higher levels of anti-tumor response compared to canonical DC formulations. These results strongly support further implementation of this DC formulation in future cancer vaccine clinical trials. 


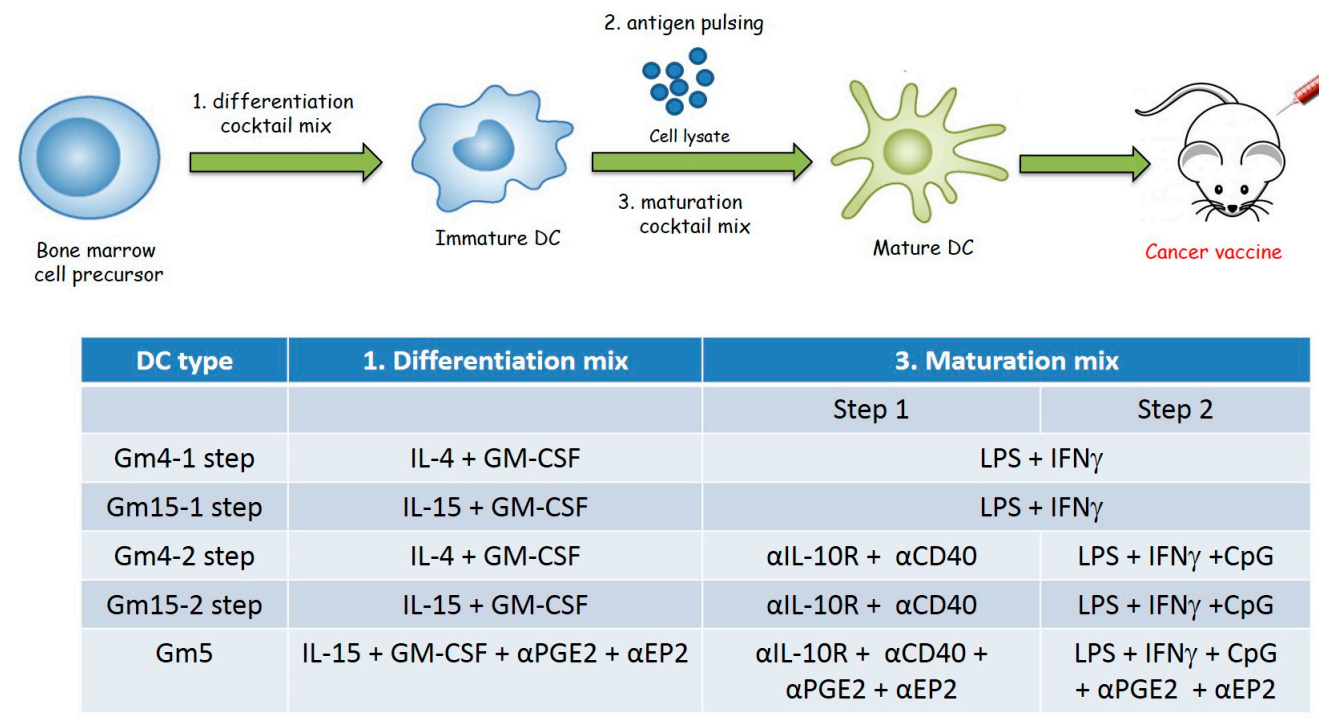

Figure 1. Schematic representation of the DC preparation protocol for animal vaccination. DC cell precursors were first isolated from the bone marrow of tumor-bearing mice and subsequently incubated with the stimuli indicated in the table for 4 days (1. differentiation mix). Immature DCs were then pulsed with squaric acid-treated ID8 cell lysate by overnight incubation. Finally, DCs were then matured by incubation with the stimuli indicated in the table (3. maturation mix). In particular, the maturation process was achieved either in one single step with $24 \mathrm{~h}$ incubation, or in two subsequent steps with incubation with the indicated reagents for $3 \mathrm{~h}$ (step 1), followed by overnight incubation with the indicated reagents (step 2). (DC: dendritic cells)

\section{Results}

2.1. Differentiation with GM-CSF and IL-15 Yields a More Immunogenic DC Phenotype than Canonical DCs Differentiated with GM-CSF and IL-4

In order to compare their immunogenic phenotype, we first differentiated DCs in vitro from the bone marrow of tumor bearing animals with GM-CSF and IL-4 (GM4-1 step DCs) or with GM-CSF and IL-15 (GM15-1 step DCs), pulsed with a squaric acid treated-ID8 tumor cell lysate (LSQ) and finally matured them with LPS plus IFN $\gamma$. After cell maturation, DC phenotypes were assessed by antibody staining against common surface markers such as: MHC-I, MHC-II, CD83, CD86, F4/80, and Toll-like receptors (TLRs) (Figure 2A, Figure S1) as well as for intracellular levels of key immunosuppressive (Figure 2B) and immunostimulatory (Figure 2C) cytokines by FACS analysis. Results showed that GM15-1 step DCs have significantly much higher MHC-II and CD86 expression, but lower MHC-I and TLR7 expression compared to GM4-1 step DCs (Figure 2A). In terms of cytokine release, although GM15-1 step DCs produced significantly lower TNF $\alpha$ and IFN $\gamma$, these DCs generated more IL-12/23p40 and less SOCS1 compared to GM4-1 step DCs. Other tested markers such as interleukin 10 (IL-10), TLR4, TLR8, transforming growth factor- $\beta$ (TGF $\beta$ ) and indoleamine 2,3-dioxygenase (IDO) did not reveal any significant changes (Figure $2 \mathrm{~A}-\mathrm{C}$ ).

Given the advantageous increase in IL-12 as well as class-II MHC and CD86, and recent data suggesting the improved efficacy DCs differentiated with IL-15 [16,27-29], we chose the GM15-1 step backbone for further improvements, focusing in particular on enhancing IFN $\gamma$ production.

In particular, based on previous evidence showing the ability of CD40 ligand to induce DC maturation and activation [30-32] and the ability of stimulated DCs to produce high levels of IL-10 [33,34], we decided to include both anti-CD40 and IL-10 receptor (IL-10R) antibodies in an attempt to improve the maturation process and achieve a more immunogenic DC phenotype. To achieve this, after differentiation with GM-CSF and IL-15 and LSQ antigen pulsing we applied the maturation stimuli in two steps, incubating DCs first with anti-CD40 plus anti-IL10R antibodies for $24 \mathrm{~h}$, followed by the well-established maturation cocktail containing LPS and IFN $\gamma$ with the addition 
of CpG (a potent TLR agonist [35]), for the subsequent $24 \mathrm{~h}$ (GM15-2 step DCs). After maturation we assessed the phenotype of these DCs by FACS analysis (Figure 3A-E).

A

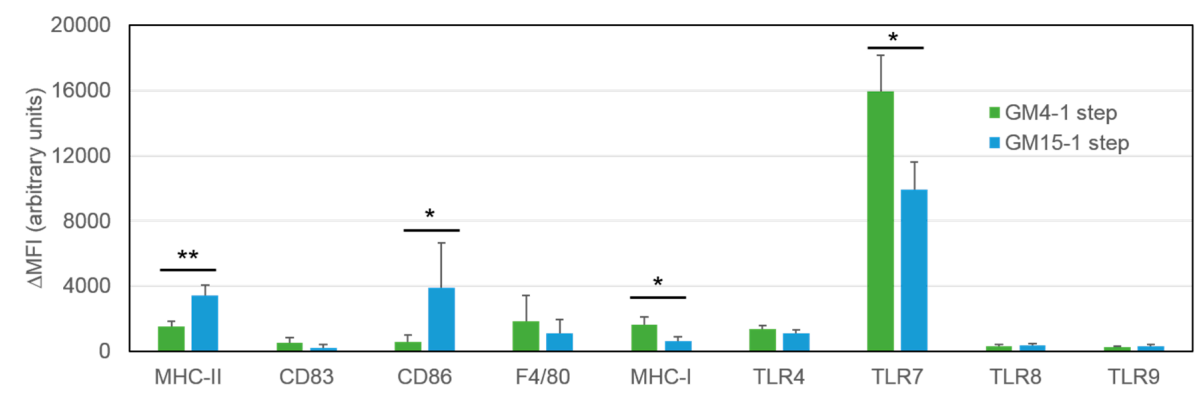

B

C
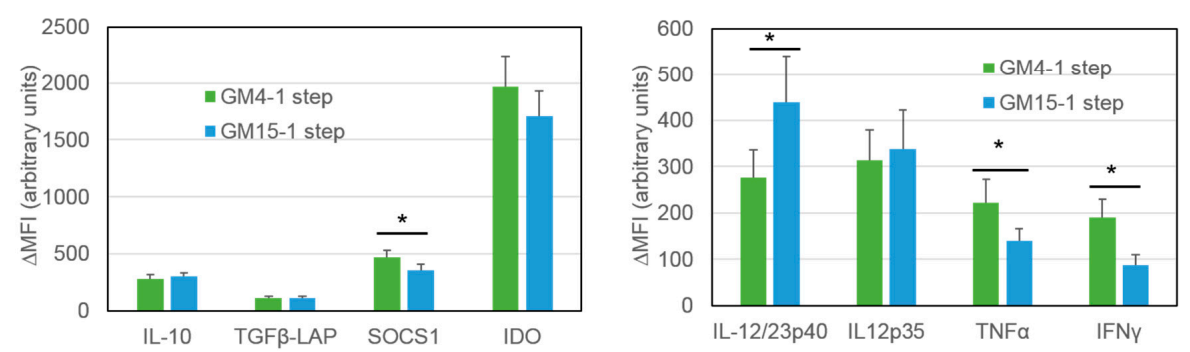

Figure 2. Phenotypic comparison between mouse DCs differentiated ex vivo from bone marrow precursors in the presence of GM-CSF and either IL-4 or IL-15. (A-C) Isolated mouse bone marrow cells were differentiated in vitro for 4 days in the presence of GM-CSF and either IL-4 (GM4-1 step) or IL-15 (GM15-1 step) as indicated, pulsed with an ID8 tumor cell lysate treated with squaric acid and subsequently matured with LPS/IFN $\gamma$. Expression levels of indicated markers were then assessed by antibody staining followed by FACS analysis. The net mean fluorescence intensity $(\triangle \mathrm{MFI}=\mathrm{Raw}$ MFI-MFI of Isotype) for each marker is reported in the graph; data are representative of 3 independent experiments. Significant differences were assessed with unpaired Student's $t$ test and indicated with asterisks: ${ }^{*} p<0.05$; ${ }^{* *} p<0.01$. (DC: dendritic cells; GM-CSF: granulocyte-macrophage colony-stimulating factor; IL-4: interleukin-4; IL-15: interleukin-15; IFN- $\gamma$ : interferon- $\gamma$; LPS: lipopolysaccharide).

Interestingly, introducing this new maturation scheme in DCs differentiated with GM-CSF and IL-15 (GM15-2 step DCs) led to a further and significant increase in MHC-II, CD86 as well as TLR4, and decrease in IDO expression, compared to IL-15 DCs matured in the presence of just LPS and IFN $\gamma$ (GM15-1 step DCs, Figure 3A,B). A significant increase in IL-12/23p40 and IFN $\gamma$ production was seen in GM15-2 step DCs compared to GM15-1 step DCs (Figure 3C).

In addition to this, we then further compared the same 2-step maturation protocol in DCs differentiated in the presence of IL-4/GM-CSF (GM4-2 step DCs), or IL-15/GM-CSF. Our results showed that the latter (GM15-2 step DCs) exhibited higher MHC-II, CD86, TLR4, IL-12/23p40, IL-12p35 and IFN $\gamma$, and lower IDO and suppressor of cytokine signaling 1 (SOCS1) relative to GM4-2 step DCs, suggesting a potentially more immunogenic phenotype (Figure 3D,E).

Next, we proceeded to compare the efficiency of these different DC formulations in eliciting anti-tumor T cell responses. To achieve this, we prepared DCs as above, we incubated them with purified T cells from the spleen of ID8 tumor bearing mice for $24 \mathrm{~h}$, and finally measured cytokines levels in the supernatant by ELISA. Results showed that GM15-2 step DCs induced significantly higher IFN $\gamma$ production compared to all the other tested DC formulations and lower IL-4 generation compared to IL-4 derived DCs, both trends indicative of a Th1-skewed T cell response (Figure 3F,G). Similar results were also obtained from $\mathrm{T}$ cells purified from mesenteric and inguinal draining lymph nodes or peritoneum (Figure S2). 
A

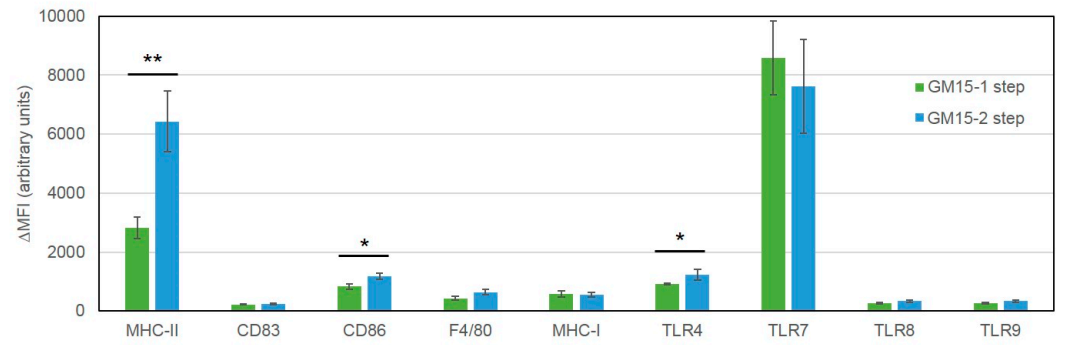

B

C
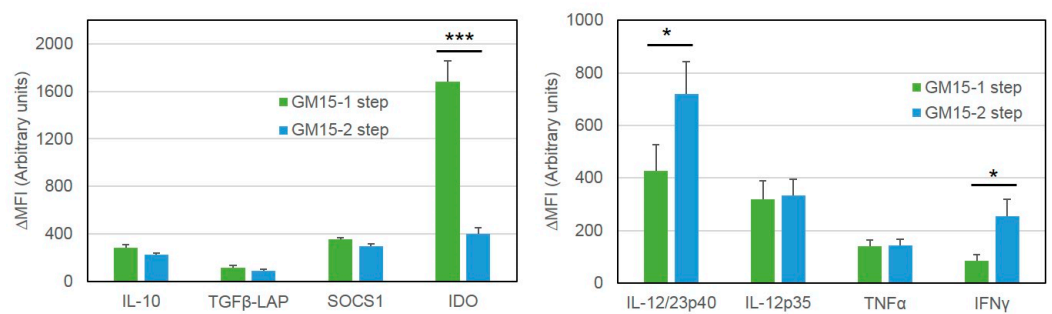

D
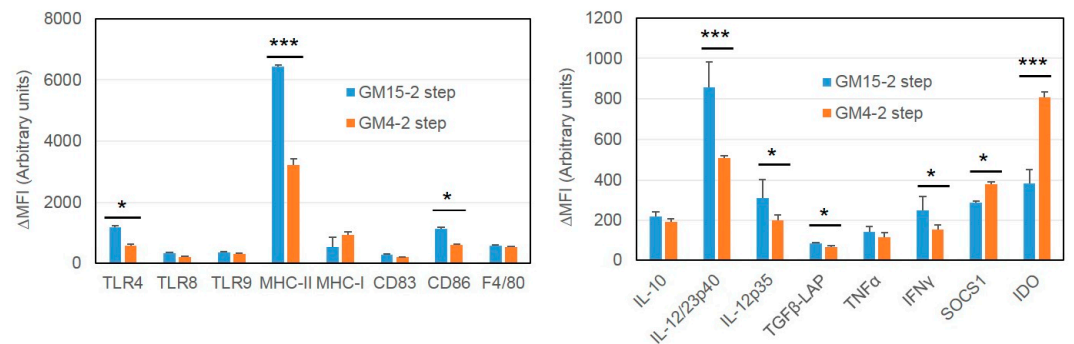

F

G
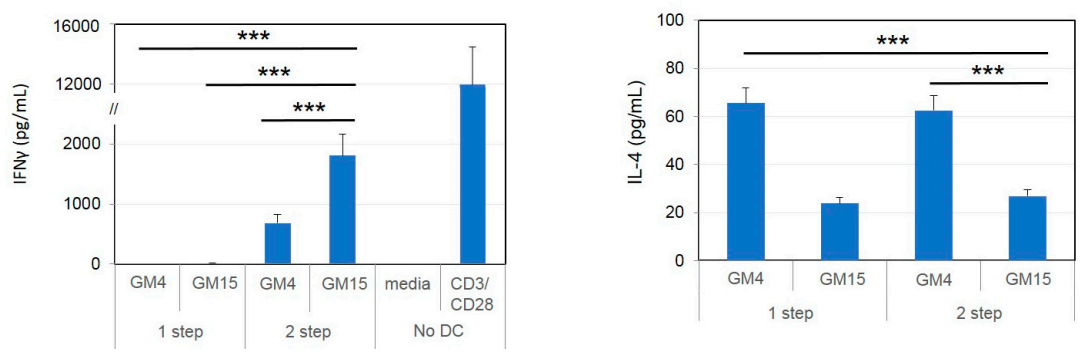

Figure 3. DCs matured with a two-step protocol in the presence of anti-CD40 and anti-IL10R antibodies for $24 \mathrm{~h}$, followed by LPS/IFN $\gamma / \mathrm{CpG}$ stimuli present a more mature phenotype and stimulate a more Th1-skewed $\mathrm{T}$ cell response compared to canonical LPS/IFN $\gamma$ maturation. (A-E) Immature antigen-pulsed DCs were obtained in the presence of either IL4 (GM4) or IL-15 (GM15) as reported in Figure 2. Cells were then pulsed with an ID8 tumor cell lysate treated with squaric acid and subsequently matured in the presence of either LPS/IFN $\gamma$ for $24 \mathrm{~h}$ (GM15-1 step, GM4-1 step) or with a cocktail mix containing anti-CD40 and anti-IL-10R for $24 \mathrm{~h}$, followed by a second mix containing LPS, IFN $\gamma$ and CpG for the subsequent 24hr (GM4-2 step, GM15-2 step). Expression levels of indicated markers were then assessed by antibody staining followed by FACS analysis. The net mean fluorescence intensity $(\triangle \mathrm{MFI}=$ Raw MFI-MFI of Isotype) for each marker is reported in the graph. (F,G) IFN $\gamma$ and IL-4 production measured by ELISA after $24 \mathrm{~h}$ co-culturing of splenic T-lymphocytes isolated from tumor bearing animals with the indicated DC formulations. Data are representative of at least 3 independent experiments. Significant differences were assessed with unpaired Student's test and indicated with asterisks: ${ }^{*} p<0.05 ;{ }^{* *} p<0.01 ;{ }^{* * *} p<0.005$. (CpG: CpG oligonucleotides; DC: dendritic cells; GM-CSF: granulocyte-macrophage colony-stimulating factor; IL-4: interleukin-4; IL-10R: interleukin-10 receptor; IL-15: interleukin-15; IFN- $\gamma$ : interferon- $\gamma$; LPS: lipopolysaccharide). 
Following in vitro studies, we proceeded to compare the efficacy of GM15-2 step DCs with the conventional GM4-1 step DCs in vivo in the ID8 ovarian cancer mouse model. To achieve this, we first inoculated ID8 cells intraperitoneally (i.p.) in C57BL/ 6 mice on day 0 and subsequently injected GM4-1 step or GM15-2 step DCs or placebo (phosphate-buffered saline (PBS)) i.p. on day 7, day 14 and day 21 post tumor inoculation, then following animal survival over time (Figure 4A). Interestingly, we observed that mice vaccinated with GM15-2 step DCs displayed a significant distinct survival advantage over mice vaccinated with conventional DCs (GM4-1 step DCs; $p<0.05)$ or placebo $(p<0.05)$ (Figure 4B). In particular, the median survival in the placebo group was $\sim 40$ days, while mice receiving GM4-1 step DCs had a median survival of about $\sim 65$ days, compared to $\sim 80$ days for the GM15-2 step DC-treated group. These results confirmed therefore the superiority of GM15-2 step DCs also in the in vivo context compared to canonical IL-4 differentiated DCs (GM4-1 step DCs).

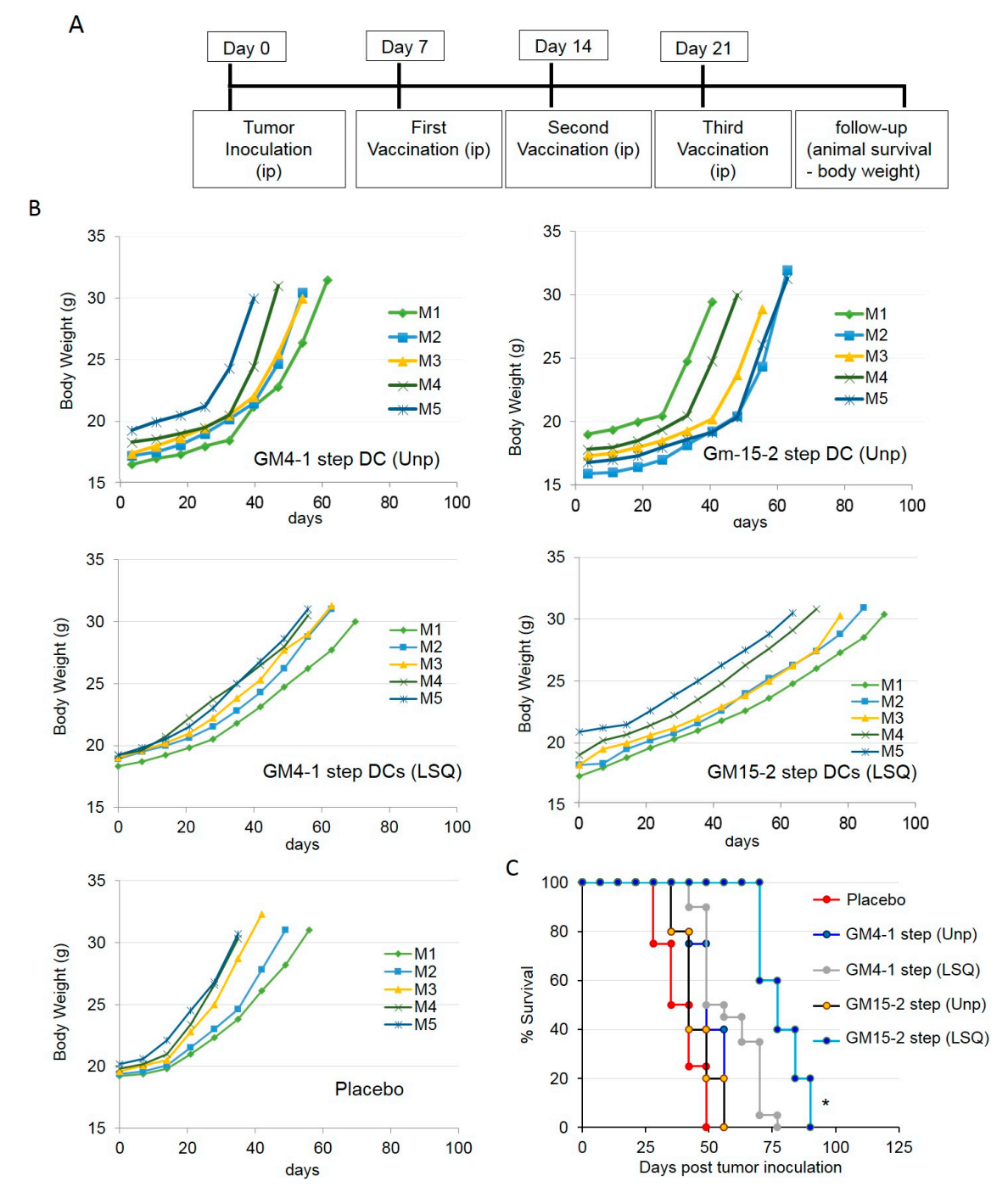

Figure 4. DCs matured with a two-step protocol in the presence of anti-CD40 and anti-IL10R antibodies for $24 \mathrm{~h}$, followed by LPS/IFN $\gamma / \mathrm{CpG}$ stimuli prolong animal survival in a vaccination mouse model of ovarian cancer. (A) Vaccination scheme: mice were inoculated i.p. with ID8 cells at day 0, followed by i.p. vaccination with the indicated DC formulations (pulsed with an ID8 tumor cell lysate treated with squaric acid (LSQ) or kept unpulsed (Unp)) at day 7, 14 and 21 ( $n \geq 5$ for each group). (B,C) Body weight and animal survival were evaluated and plotted in Kaplan-Meier cumulative survival plots. Student's t test results (comparing GM15-2 step DCs (LSQ) to both GM4-1 step DCs (LSQ) and placebo) is indicated with an asterisk: ${ }^{*} p<0.05$. (CpG: CpG oligonucleotides; DC: dendritic cells; IFN- $\gamma$ : interferon- $\gamma$; LPS: lipopolysaccharide). 


\subsection{Improving the Efficacy of GM15-2 Step DCs through Inhibiting the Prostaglandin Pathway}

Based on previous evidence suggesting an immunosuppressive activity of PGE2 on DC differentiation [36], function [37,38] and IL-12 production [36], we next focused on further improving our DC preparation protocol to achieve an even more immunogenic DC vaccine by introducing an antibody against PGE2 and one against its putative receptor EP2 throughout the DC culture. The phenotype of the resultant DCs (DC5) was then assessed by antibody staining followed by FACS analysis (Figure 5A,B). Results showed significantly increased levels of MHC-I, MHC-II, IL-12p35, IL12/23p40 and IL-1 $\alpha$ in DC5, compared to the previously developed GM15-2 step DCs, while CD86, TNF $\alpha$ and cytokine-inducible nitric oxide synthase (iNOS) levels were essentially comparable (Figure 5A,B).

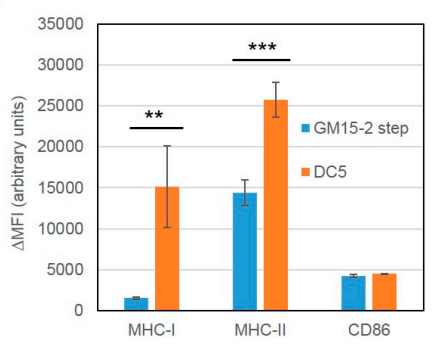

C

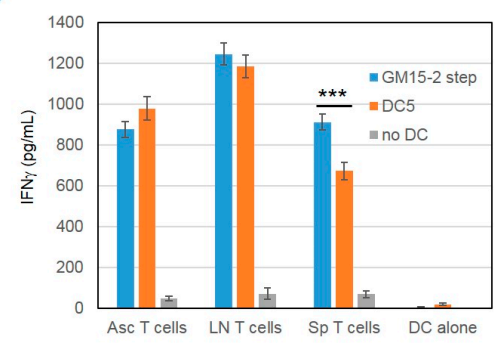

E

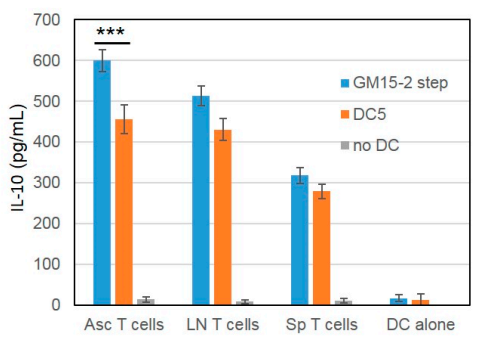

B

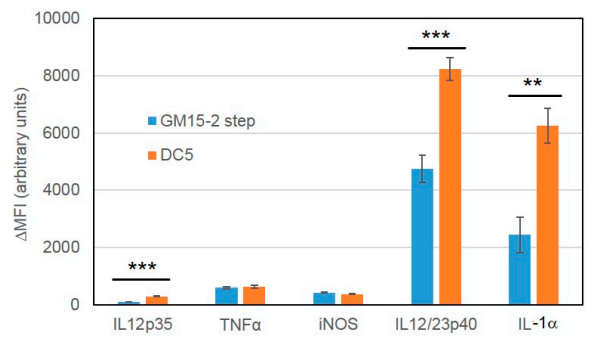

D

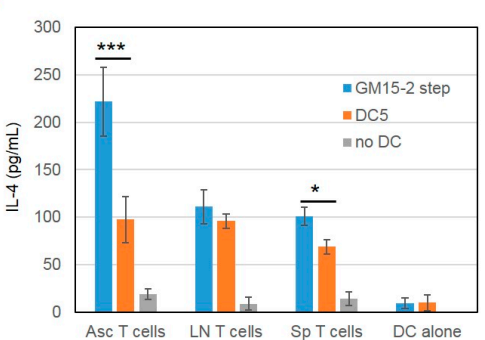

$\mathrm{F}$

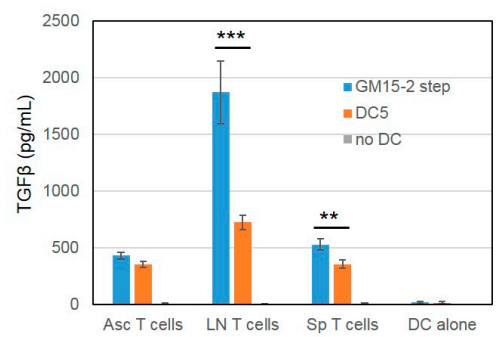

Figure 5. Blocking the prostaglandin $\mathrm{E}_{2}$ pathway during $\mathrm{DC}$ differentiation and maturation improves DC phenotype and in vitro immunogenicity. (A,B) Isolated mouse bone marrow cells were differentiated in the presence of GM-CSF and IL-15 (GM15-2 step DCs) for 4 days or first with GM-CSF and IL-5 for $24 \mathrm{~h}$ then supplemented with anti-PGE2, anti-EP2 Ab (DC5); cells were then pulsed and matured as reported in Figure 3 for GM15-2 step DCs with the addition of anti-PGE2, anti-EP2 Ab for DC5 throughout the cell culturing period. Cell phenotype was then analyzed by FACS staining and the net mean fluorescence intensity $(\triangle \mathrm{MFI}=$ Raw MFI-MFI of Isotype) for each marker was reported in the graph. (C-F) Levels of indicated cytokines measured by ELISA, produced after $24 \mathrm{~h}$ co-culturing of T-lymphocytes isolated from the ascites (Asc), lymph node (LN), or spleen (Sp) of tumor bearing animals with the indicated DC formulations pulsed with an ID8 tumor cell lysate treated with squaric acid. Data are representative of at least 3 independent experiments. Significant differences were assessed with unpaired Student's $\mathrm{t}$ test and indicated with asterisks: ${ }^{*} p<0.05$; ** $p<0.01$; *** $p<0.005$. (CpG: CpG oligonucleotides; DC: dendritic cells; EP2: PGE2 receptor; GM-CSF: granulocyte-macrophage colony-stimulating factor; IL-15: interleukin-15; PGE2: prostaglandin E2). 
We then tested the in vitro induced T-cell responses by co-culturing GM15-2 step DCs or DC5 (prepared from bone marrow cells of tumor bearing animals) with T cells derived from ascites, spleen or draining lymph nodes of tumor bearing animals for $24 \mathrm{~h}$ and subsequently measuring levels of IFN $\gamma$, IL-4, TGF $\beta$ and IL-10 in the culture supernatant by ELISA. Results showed that while levels of IFN $\gamma$ were essentially comparable between the two different DC preparations in use (when comparing between same T cells types, Figure 5C; except in the case of splenic T cells), IL-4 and IL-10 levels were significantly lower in co-cultures of ascites T cells with LSQ antigen-pulsed DC5 DCs compared to the respective GM15-2 step DC counterpart (Figure 5D,E). DC5 DCs also induced significantly less IL-4 when co-cultured with splenic T cells compared to GM15-2 step DCs (Figure 5D). Finally, LSQ antigen-pulsed DC5 elicited significantly lower amounts of TGF $\beta$ in co-cultures of lymph node and splenic T cells compared to GM15-2 step DCs (Figure 5F). Thus, the in vitro results here presented, taken collectively, suggest that DC5 display a more advantageous DC phenotype than the previously characterized GM15-2 step DCs, they induce a more favorable cytokine profile in co-cultured T cells and they can be therefore considered more immunogenic.

We next proceeded to test the therapeutic efficacy of DC5 in vivo. To achieve this, we injected i.p. 8-10 week old female mice with ID8 cells on day 0. We then injected i.p. placebo (PBS), GM15-2 step or DC5 unpulsed or LSQ antigen-pulsed on days 7, 14 and 21 post tumor inoculation and followed animal survival over time. We observed that therapeutic vaccination with antigen-pulsed DC5 could significantly $(p<0.01)$ delay tumor progression and impart a much higher survival advantage compared to vaccination with LSQ antigen-pulsed GM15-2 step DCs or classical GM4-1 step DCs (Figure 6A-C). While the median survival for placebo controls was 36 days post inoculation, this increased to 49 days with therapeutic vaccination with LSQ antigen-pulsed GM4 DCs, to 65 days with GM15-2 step DCs and to 110 days with DC5 DCs.

A
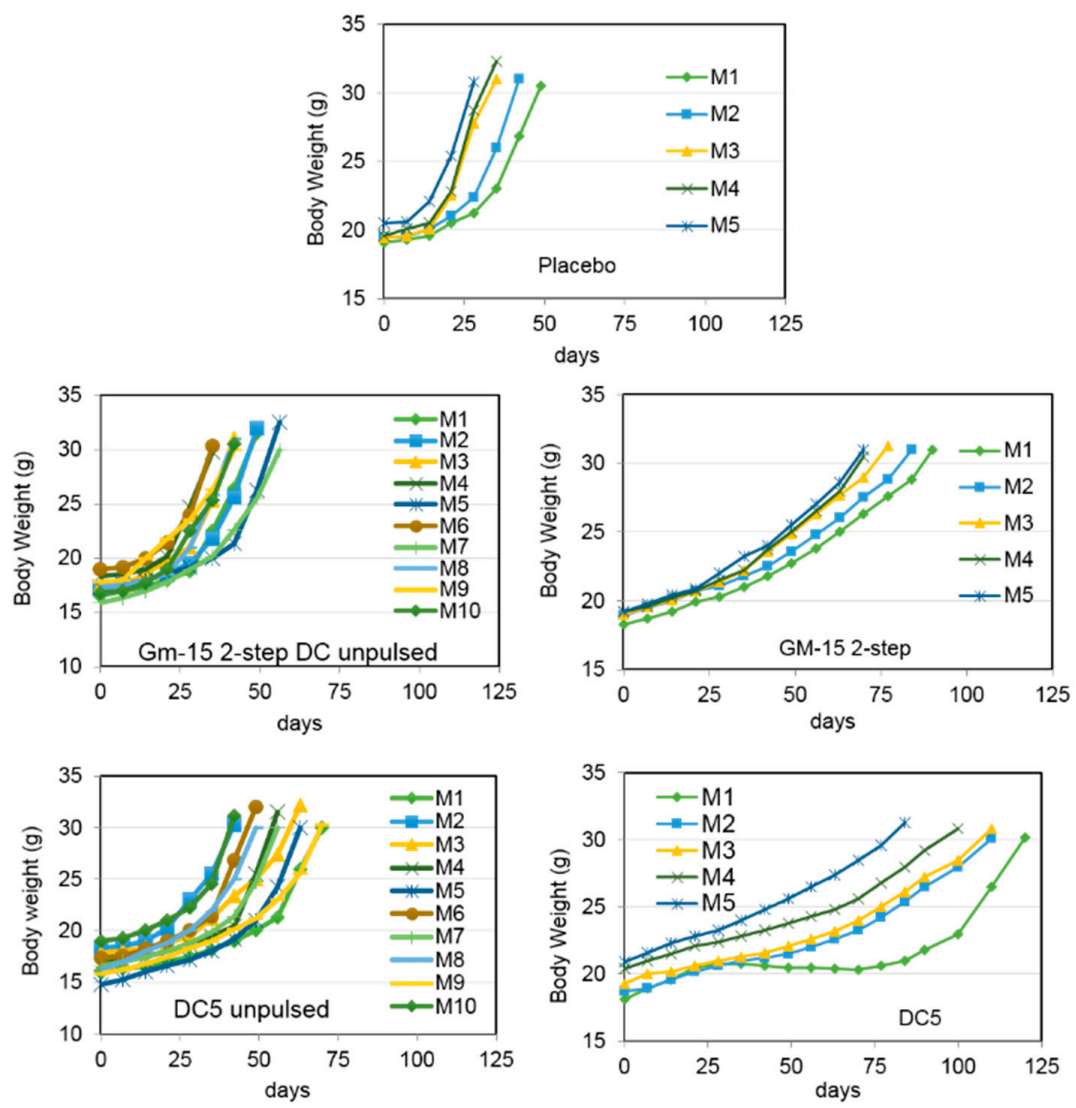

Figure 6. Cont. 
B

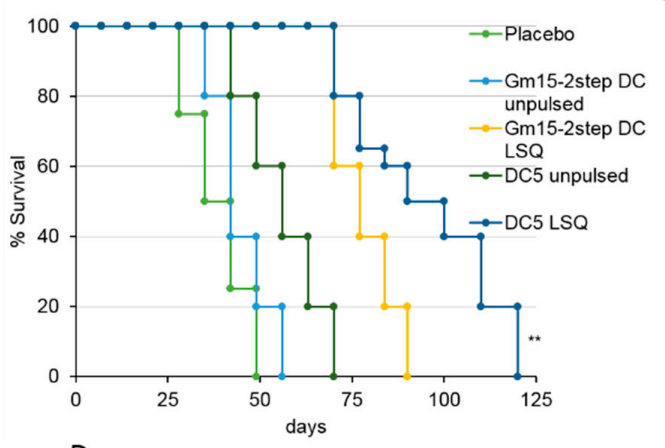

D

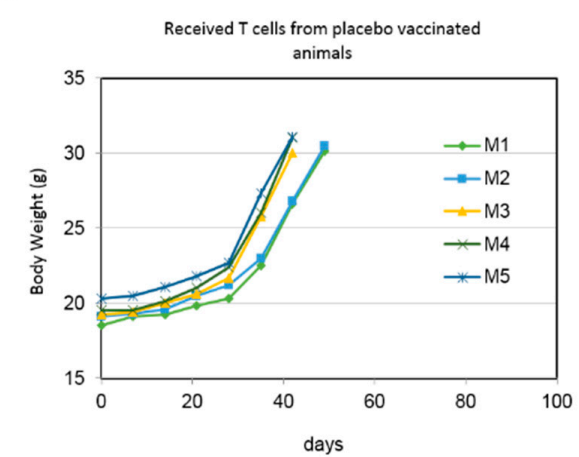

C

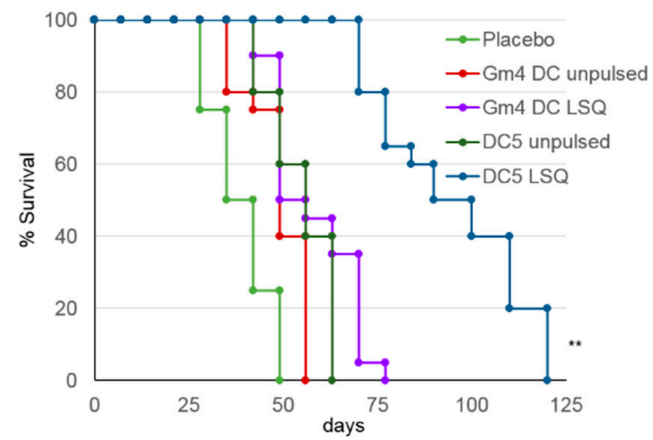

Received T cells from DC5 vaccinated animals

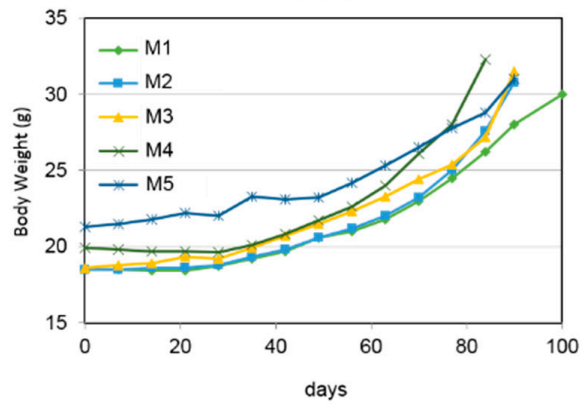

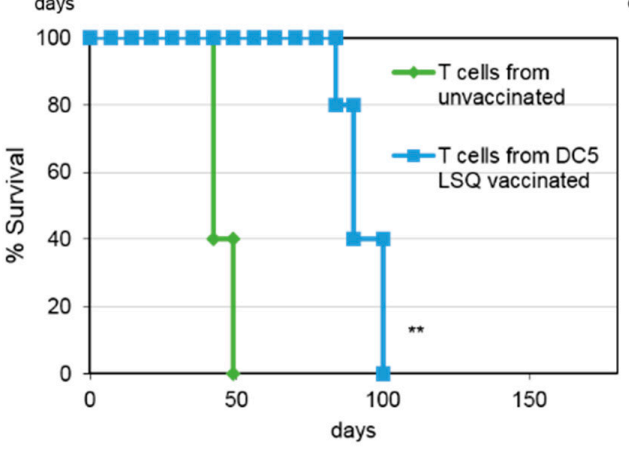

Figure 6. Blocking the prostaglandin $\mathrm{E}_{2}$ pathway during DC differentiation and maturation prolongs animal survival in a vaccination mouse model of ovarian cancer. (A-C) Mice were inoculated i.p. with ID8-fast cells at day 0, followed by i.p. vaccination with the indicated DC formulations at day 7,14 and 21 ( $n \geq 5$ for each group). Body weight and animal survival were evaluated and plotted in Kaplan-Meier cumulative survival plots. Student's t test results (comparing DC5 LSQ DCs to both GM15-2 step LSQ and classical GM4-1 step LSQ DCs) are indicated with an asterisk: ${ }^{* *} p<0.01$ (D) Animals were vaccinated as reported above; T cells were then isolated from inguinal LN on day 28 post tumor inoculation and injected in the tail vein of recipient mice 3 days before tumor challenge with i.p. injection of ID8 fast cells. Body weight and animal survival were evaluated and plotted in Kaplan-Meier cumulative survival plots. Student's $t$ test results are indicated with an asterisk: ** $p<0.01$. (DC: dendritic cells).

To test the tumor specificity of the $\mathrm{T}$ cell response as well as the memory response elicited by therapeutic vaccination with DC5 DCs, we then performed adoptive T cell transfer experiments. The donors were ID8 tumor bearing female C57BL/ 6 mice, either kept untreated or therapeutically treated with DC5 (i.p.) on days 7, 15 and 21 post tumor inoculation. Lymph node (LN) cells were then collected from inguinal LN on day 28 post tumor inoculation and T cells isolated by negative selection. T cells were then injected in the tail vein of recipient mice 3 days before tumor challenge with i.p. injection of ID8 cells. Animal survival measurements presented in Figure 6D showed that T cells from lymph nodes of animals therapeutically vaccinated with DC5, when transferred to naïve animals, 
conferred considerable prophylactic protection and delayed tumor establishment and progression compared to that conferred by $\mathrm{T}$ cells from placebo controls.

\subsection{Characterization of the T Cell Response Induced by Vaccination with DC5 DCs}

Based on the fact that vaccination with the DC5 formulation conferred the highest survival advantage in the present study, we decided to further characterize its induced T cell response and compare it with the one elicited by classical GM4-1 step DC vaccination which is the current golden standard for DC vaccines in clinical settings. To achieve this, we first established metastatic tumors by injecting i.p. ID8 cells (day 0) in 8-10 week old female C57BL6 mice, followed by i.p. vaccination with DCs (or placebo) on days 7, 14 and 21 post tumor inoculation. Then, at 42 days post tumor inoculation, we isolated cells from the peritoneal cavity and performed a flow cytometric analysis for different markers of cell cytotoxicity. Interestingly, we observed that in the $\mathrm{CD} 8^{+}$cell compartment both the expression (in terms of $\Delta \mathrm{MFI}$ ) and the percentage of granzyme $\mathrm{B}^{+} \mathrm{T}$ cells were significantly higher in DC5 vaccinated animals compared to animals vaccinated with GM4-1 step DCs or placebo (Figure 7A). A similar analysis was also repeated for $\mathrm{CD} 8^{+} \mathrm{T}$ cells isolated by negative selection from draining lymph nodes and spleen, showing that DC5 vaccination induced significantly higher levels of granzyme $\mathrm{B}^{+} \mathrm{T}$ cells also in these animal loci compared to the other two conditions (authors personal observation). Additionally, in the peritoneum cell compartment we also observed that, although the percentage of $\mathrm{CD}^{+} \mathrm{T}$ cells expressing IL-10 was comparable between animals vaccinated with GM4-1 step DCs and DC5, the amount expressed (in terms of $\triangle \mathrm{MFI}$ ) in the latter case was significantly lower (Figure 7B). Interestingly, $\mathrm{CD} 45^{+}$peritoneal cells form DC5 vaccinated animals also presented higher expression (in terms of $\Delta \mathrm{MFI}$ ) and percentage of perforin ${ }^{+}$cells compared to control counterparts (Figure 7C).

A
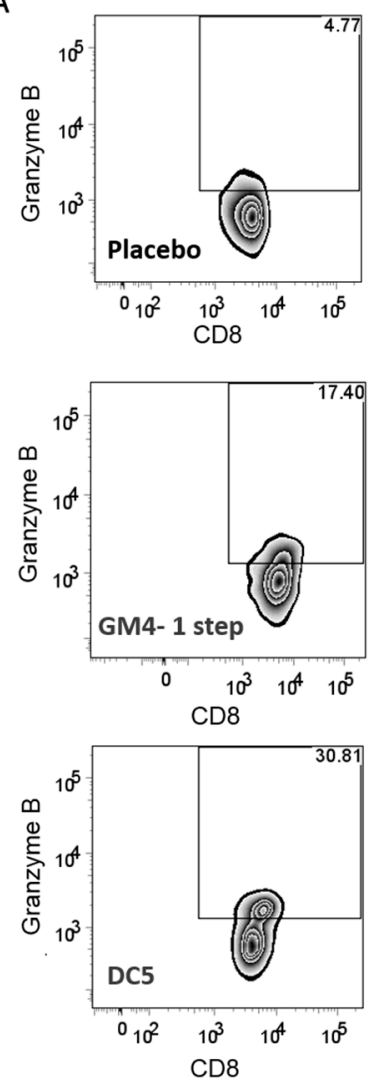

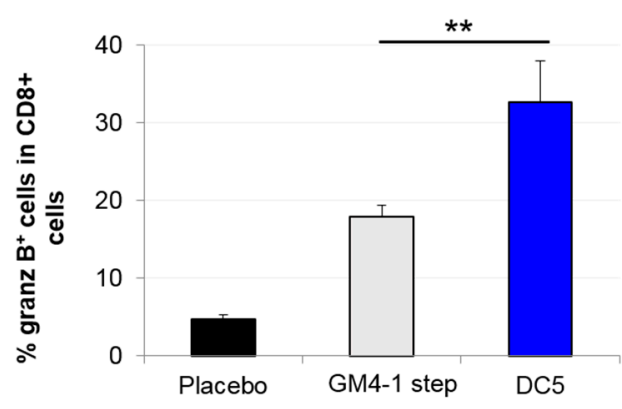

Granzyme B expression

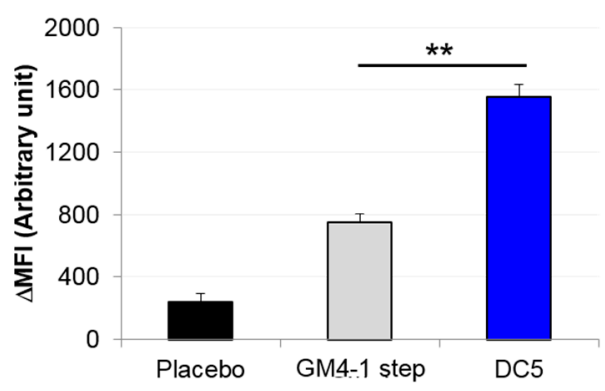

Figure 7. Cont. 
B
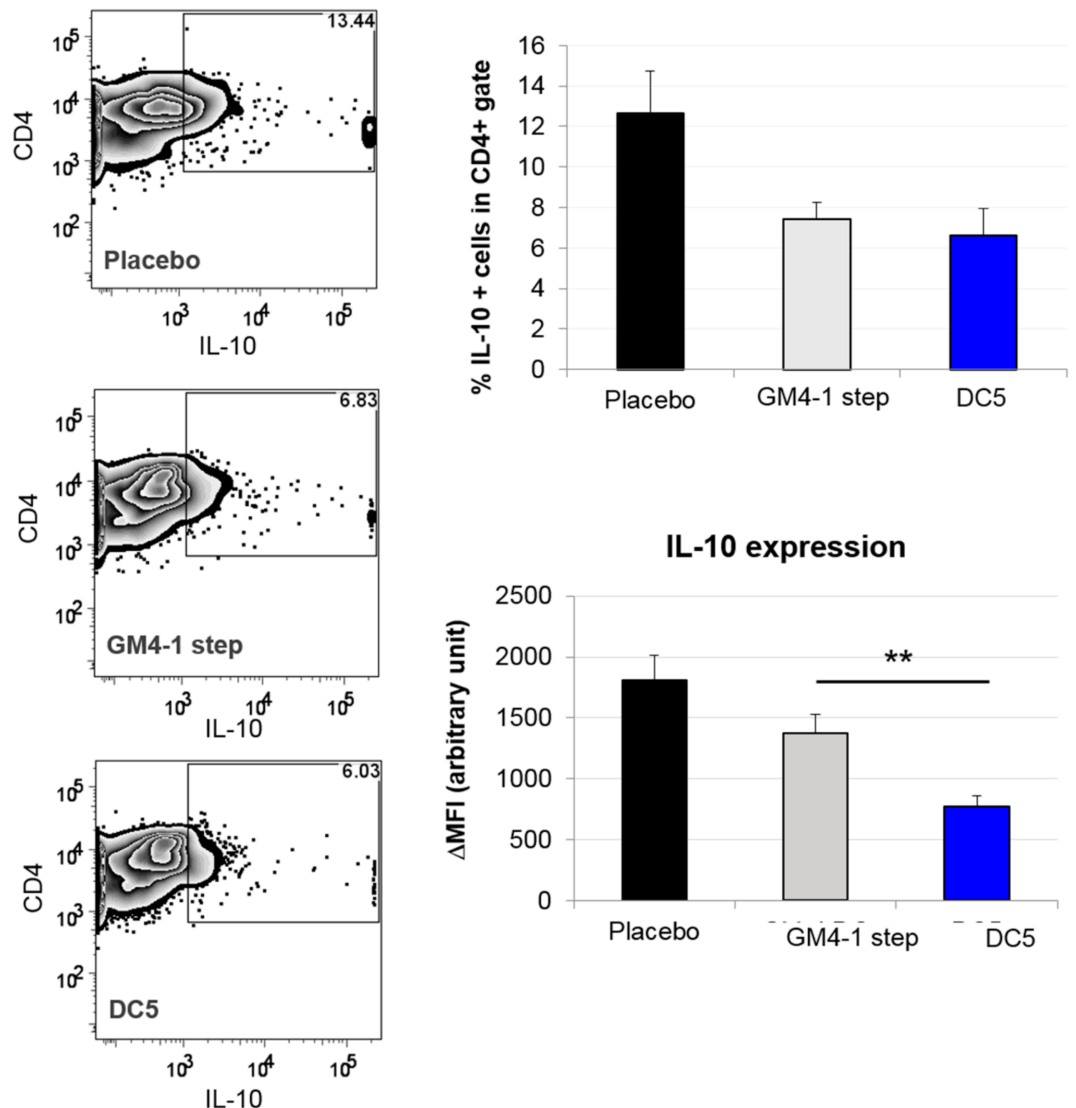

C
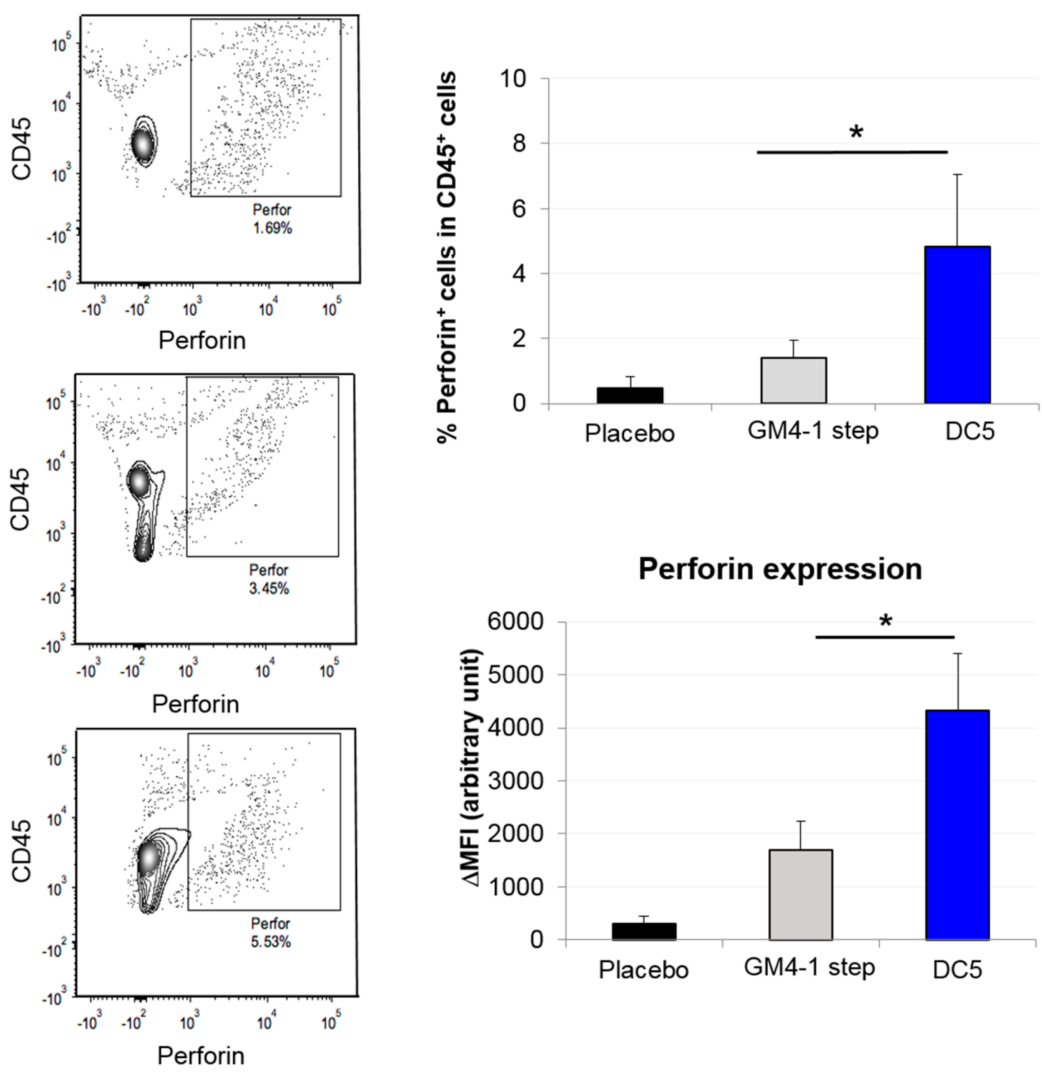

Figure 7. Cont. 
D

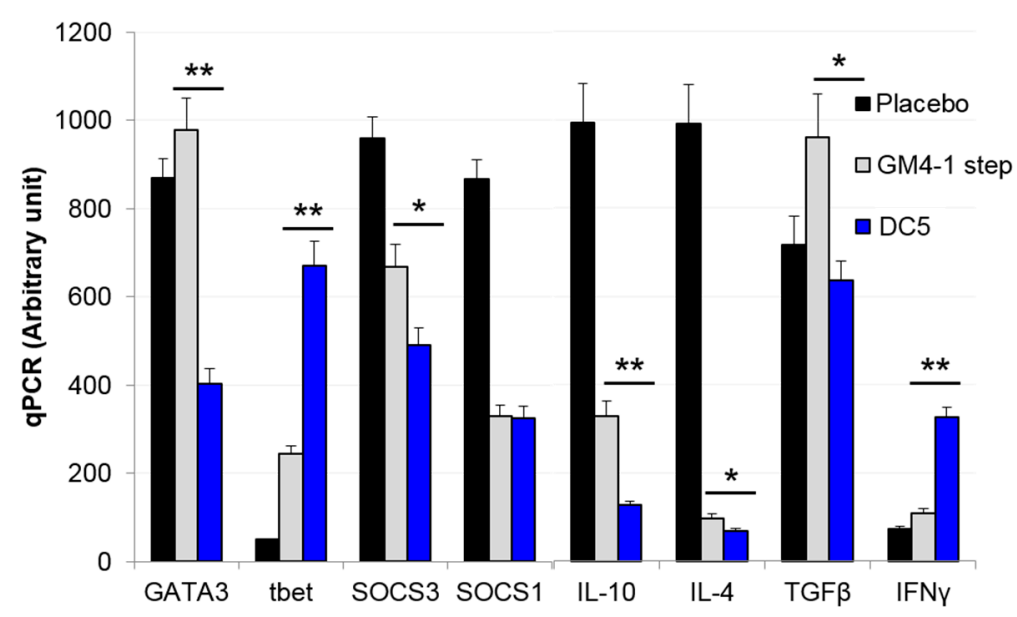

Figure 7. Vaccination with DC5 DCs increases cell activation and cytotoxicity of the T cell compartment at tumor site. (A-C) ID8 fast cells were injected i.p. in 8-10 weeks old female C57BL6 mice; mice were then vaccinated i.p. with the indicated DC formulation (or placebo) on day 7, day 14 and day 21 post tumor inoculation. 42 days post tumor inoculation cells isolated from the ascite fluid (in the case of placebo control animals) or obtained by peritoneal lavage (in vaccinated animals that presented no ascites) were stained with the indicated markers and analyzed by flow cytometric analysis. (D) mRNA levels of indicated markers were analyzed by qPCR in $\mathrm{CD} 45^{+}$cells isolated as reported above. Data are representative of at least 3 independent experiments. Significant differences were assessed with unpaired Student's t test and indicated with asterisks: ${ }^{*} p<0.05 ;{ }^{* *} p<0.01$. (DC: dendritic cells; qPCR: quantitative polymerase chain reaction).

Given that we used an intra-peritoneal model of ovarian cancer, we also performed a qPCR analysis of the whole $\mathrm{CD} 45^{+}$population from peritoneum of vaccinated animals to get a better understanding of the tumor microenvironment. Analyses showed that DC5 vaccinated animals were characterized by significantly lower GATA3, SOCS3, IL-10, IL-4, TGF- $\beta$ mRNA and higher tbet and IFN $\gamma$ levels compared to GM4-1 step vaccinated animals; all indicative of a Th1-skewed T cell response (Figure 7D).

Finally, we cultured T cells isolated from vaccinated animals with autologous DCs pulsed with LSQ (or unpulsed DCs in case of placebo), in the presence of IL-12 for $24 \mathrm{~h}$ and analyzed cytokine levels by qPCR. T cells isolated from the peritoneum of animals vaccinated with DC 5 were superior in terms of perforin, granzyme $B, I F N \gamma$ and IL-9 mRNA levels compared to both the respective placebo and classical GM4-1 step DC counterparts (Figure 8A). In the instance of $\mathrm{T}$ cells isolated from draining lymph nodes, DC5 vaccination induced higher granzyme B and IL-9 mRNA levels compared to GM4-1 step vaccination; while perforin and IFN $\gamma$ levels were comparable between the two conditions (Figure $8 \mathrm{~B}$ ). On the other hand, T cells isolated from the spleen of DC5 vaccinated animals showed lower granzyme $B, I F N-\gamma, T G F-\beta$ and IL-10 mRNA levels, compared to GM4-1 step vaccinated animals (Figure 8C).

These results, and in particular the pronounced perforin 1, granzyme $B$, IFN $\gamma$, and IL-9 mRNA expression by peritoneal T cells along with low levels of $I L-10$ and TFG $\beta$ mRNA are indicative of a high anti-tumor effector potential induced by vaccination with DC5 DCs. 
A

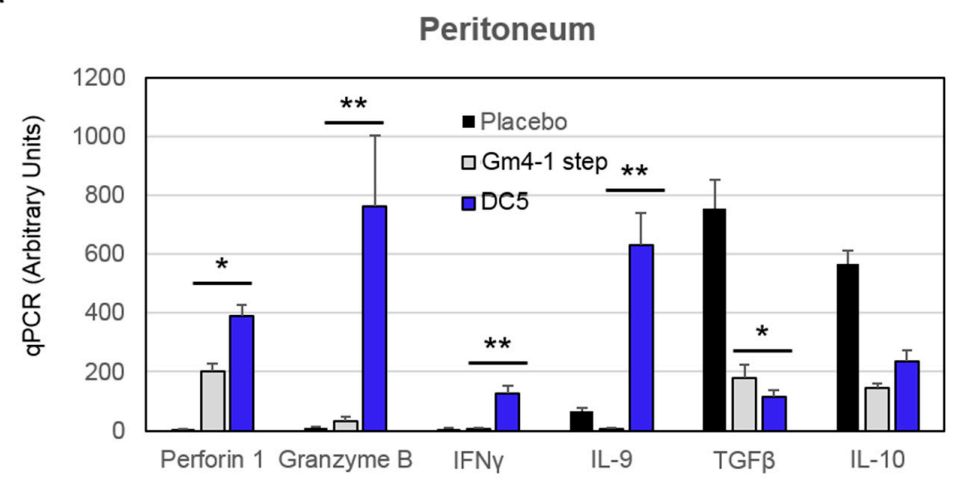

B

Draining lymph node

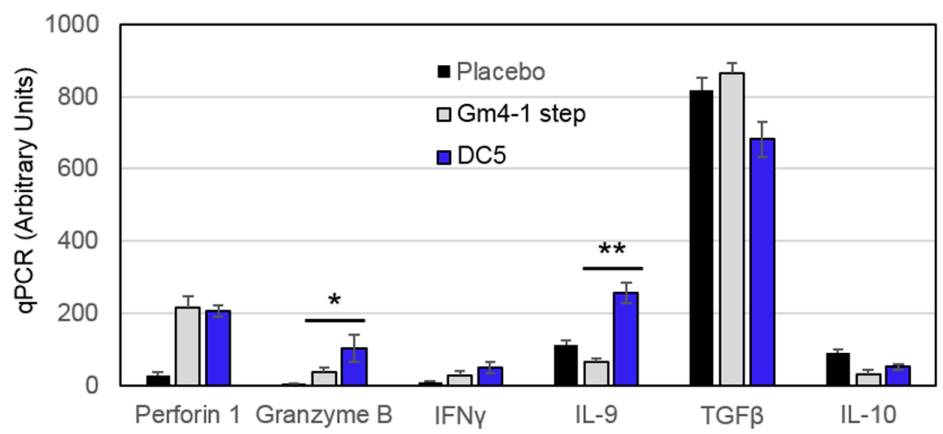

C

Spleen

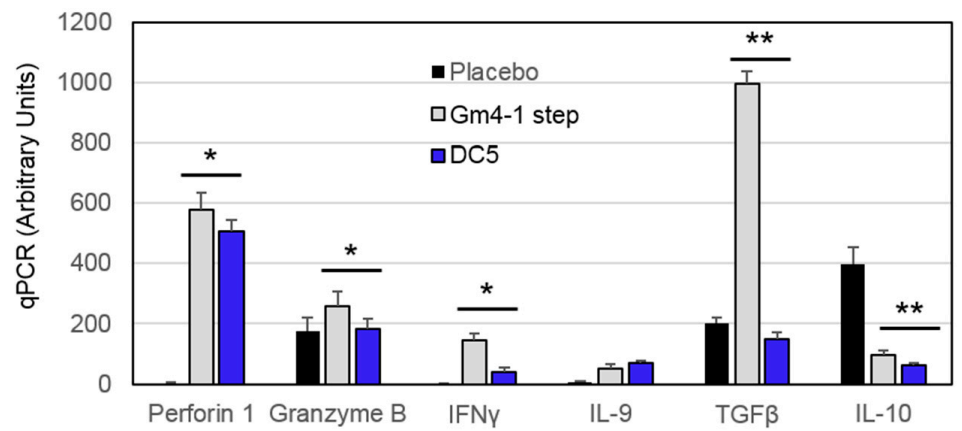

Figure 8. T cells isolated from DC5-vaccinated animals and stimulated ex-vivo with IL-12 present a more activated and cytotoxic mRNA profile. (A-C) T cells isolated from animals vaccinated as reported in Figure 6 were cultured for $24 \mathrm{~h}$ in the presence of IL-12. mRNA levels of indicated markers were then analyzed by qPCR. Data are representative of at least 3 independent experiments. Significant differences were assessed with unpaired Student's $t$ test and indicated with asterisks: ${ }^{*} p<0.05 ;{ }^{* *} p<$ 0.01. (IL-12: interleukin-12).

\section{Discussion}

It is known that GM-CSF and IL-15 can differentiate both mouse bone marrow cells and human $\mathrm{CD}^{+} 4^{+}$monocytes into DCs (IL-15 DCs) [18,39]. Recently, it has been shown that these DCs can efficiently initiate both Th1 and Th17 responses [17] and mount an anti-cancer immune response against melanoma [40]. Thus, several groups subsequently brought these cells into clinical trials for cancer therapeutics with moderate success (NCT01456104, NCT01189383) [16,41]. On the other hand, DCs differentiated in the presence of GM-CSF and IL-4 (IL-4 DCs) represent the gold standard for DC therapeutic vaccination and have been tested in clinical trials for more than 20 years [42]. Despite the many efforts and advancements over the years, data meta-analysis demonstrated that this therapeutic 
intervention could only increase overall survival by $20 \%$, to date [43]. Given the crucial role played by DCs in orchestrating both innate and adaptive immune responses it is generally believed that new improvements could further improve clinical outcomes and harness the true therapeutic potential of DCs. In search for a more powerful vaccine, we compared the efficacies of IL-15 DCs and IL-4 DCs in the context of a metastatic murine ovarian cancer model. Differentiation of bone marrow cells to DCs in the presence of GM-CSF and IL-15, followed by the same maturation stimuli as conventional IL-4 DCs, resulted in higher CD86, MHC-II expression and higher IL-12p40 generation compared to the latter, indicating that this DC preparation expresses more co-stimulatory molecules and might be better equipped to activate $\mathrm{T}$ cell responses skewed towards a Th1 type. However, these DCs generated lower amounts of IFN $\gamma$ and TNF $\alpha$ and similar IL-10 production to that produced by conventional GM4-1 step DCs.

The CD40/CD40L axis is an important licensing signal that enables DCs to subsequently prime naïve cytotoxic $\mathrm{T}$ lymphocytes [44] and CD40 ligands have also been previously shown to be potent inducers of DC maturation and activation [30-32]. On the other hand, it is well known that after stimulation, dendritic cells produce high levels of IL-10 [33,34], one of the most potent immunosuppressive cytokines, partially hampering DC full maturation. Previous evidence suggests that the addition of an anti-IL10 antibody blocks these IL-10 autocrine immunosuppressive effects, leading to increase DC maturation and T cell activation [33]. Hence, based on this collective evidence we then further introduced a blocking antibody against the IL10 receptor and a CD40 ligand during the first step of the maturation process in an attempt to further improve DC efficacy. In the last $24 \mathrm{~h}$ of the maturation process we further introduced LPS, IFN $\gamma$ and $\mathrm{CPG}$, three canonical maturation stimuli, to ensure full maturation status. Phenotypic analysis of the so-obtained DCs showed a drastic reduction of IDO expression, and an increase in IL-12/23p40, TLR4 and MHC-II expression, compared to classical LPS/IFN $\gamma$ maturation. Interestingly, previous observations demonstrated the role of CD40L in upregulating TLR4 expression [45], suggesting that, in our case, pre-incubation of DCs with CD40L may indeed induce higher TLR4 expression leading to a higher responsiveness to subsequent LPS stimulation (a known putative TLR4 ligand), ultimately promoting a higher DC maturation status. Either way, as a consequence of their higher immunogenic phenotype, GM-15-2 step DCs elicited a T-cell response strongly skewed toward Th1 when co-cultured with splenic, lymph node or peritoneal $\mathrm{T}$ cells isolated from tumor bearing animals, when compared to those elicited by canonical GM4-1 step, GM4-2 step or GM15-1 step control counterparts. A corresponding significant improvement on overall survival was also observed in a mouse model of ovarian cancer upon therapeutic vaccination with GM15-2 step DCs.

Previous observations demonstrated that a strong interplay exists between malignant cells and host cells present in the tumor proximity (e.g., tumor-associated macrophages and fibroblasts, $\mathrm{T}$ cells, etc.) to create a tumor-promoting and immunosuppressive tumor microenvironment (TME) [46,47]. One of the major players in this context is prostaglandin $\mathrm{E}_{2}$ (PGE2), a lipid metabolite produced by cyclooxygenase enzymes (COX1-2) whose activity has been linked to tumor progression [48] and inversely correlated with $\mathrm{CD} 8^{+} \mathrm{T}$ cell tumor infiltration and patient survival [49]. Several studies demonstrated that, in addition to inhibiting T cell interleukin-2 (IL-2) production [50], proliferation [50] and tumor infiltration [49], PGE2 has also a major impact during the DC early stage development, inducing a shift towards an immunosuppressive activity [37,38], impairing DC differentiation, IL-12 production [36], DC function [37,38], promoting the development of tolerogenic DCs [38] and hence overall contributing to DC dysfunction in cancer [51]. Based on this evidence, we therefore decided to introduce PGE2 and PGE2 receptor-blocking antibodies during both DC differentiation and maturation process, in an attempt to counteract these actions [52]. Indeed, our results demonstrated that inhibiting PGE2 signaling improved DC phenotype and yielded a marginal survival advantage in vivo. In fact, the so-obtained DCs (designated as "DC5") not only expressed higher levels of MHC-I and MHC-II, IL-12 and IL-1 $\alpha$ compared to GM15-2 step DCs, but also elicited an in vitro strong Th1 response marked by high IFN $\gamma$ and low IL-4, TGF $\beta$ and IL-10 from T cells isolated from different compartments of tumor 
bearing animals. While generally comparable to the GM15-2step induced ones, these responses were even improved in certain instances according to the different tested $\mathrm{T}$ cell compartments. Furthermore, when tested in vivo in the ID8 ovarian cancer mouse model, DC5 proved to be a much stronger therapeutic vaccine compared to GM15-2 step DCs, conferring appreciable survival advantage as well as a tumor specific memory response, as indicated by adoptive transfer experiments. $T$ cells isolated from animals therapeutically vaccinated with DC5 DCs in fact conferred a considerable survival advantage and delayed tumor progression when transferred to naïve animals, compared to $\mathrm{T}$ cell transfer from placebo controls, demonstrating the tumor specificity of the DC5-induced response. Furthermore, characterization of the T cell compartment from vaccinated animals showed that DC5 vaccination is able to induce a more immunogenic and cytotoxic $\mathrm{T}$ cell profile. In particular, $\mathrm{T}$ cells in the tumor proximity (peritoneum) presented higher perforin, granzyme B, lower IL-10 and a more beneficial mRNA profile, compared to classical GM4-1 step vaccination. These data, taken collectively strongly suggest that the protocol here developed for differentiation and maturation of DC5 DCs from their bone marrow precursors constitute a valid and more beneficial alternative to standard DCs obtained with "canonical" IL-4, LPS and IFN $\gamma$ stimuli. Furthermore, the work here presented was carried out with immune cells obtained from tumor-bearing mice. This aspect is of crucial importance considering previous studies reporting several important functional and numeric deficiencies of DC induced by tumors [53-56], further strengthening the evidence here presented in a more physiological and clinically relevant context.

On the other hand, despite the fact that DC5 vaccination appreciably increased the median survival against a huge metastatic tumor load, these DCs still failed to cure mice in the present study, partly due to the aggressiveness of this tumor model and partly due to the complicated tumor microenvironment which is driving the field towards combinatorial therapy. Recently, it has been proposed that the therapeutic effects of DC vaccines could be potentially further boosted with their use in combination with checkpoint blockade inhibitors such as cytotoxic T-lymphocyte-associated protein 4 (CTLA-4) and Programmed cell death protein 1 (PD-1) blocking antibodies [10]. In fact, in this way, while on one side the $\mathrm{DC}$ vaccine would stimulate a tumor-specific $\mathrm{T}$ cell response, on the other, immune checkpoint inhibitors would further sustain the clonal expansion and cytotoxicity of these DC vaccine-induced T cells. Hence, we envisage that future work should test and address this tantalizing hypothesis with improved DC formulations such as DC5 both in the mouse model and in the clinic to potentially improve therapeutic outcomes of DC vaccines, especially in the case of more advanced stage tumors.

\section{Materials and Methods}

\subsection{Reagents}

Recombinant murine GM-CSF, IL-4, IL-15 and IFN $\gamma$ were purchased from Peprotech, Rocky Hill, NJ, USA. Anti-IL-10R (CD210) antibody was purchased from Biolegend, San Diego, CA, USA. Anti-CD40 monoclonal antibody (FGK-45) was procured from Enzo Lifesciences, Farmingdale, NY, USA. All fluorescent antibodies and their isotype controls were purchased from Biolegend, USA unless stated otherwise. Anti-IL-12p35-eFluor660, anti-IL-10-PE, anti-TNF $\alpha$-PE/Cy7, anti-IFN $\gamma$-APC, anti-IL-12/23p40-PerCP/Cy5.5, anti-TLR9 (CD289)-biotin, anti-Thymic stromal lymphopoietin (TSLP) functional grade antibodies and Human/Murine TGF $\beta$ ELISA kit were purchased from eBiosciences, Waltham, MA, USA. Anti-TGF $31-L A P$ antibody was purchased from Thermo Scientific, Waltham, MA, USA. Anti-SOCS1 and anti-SOCS3 antibodies were purchased from Millipore (Upstate), Burlington, MA, USA. Anti-Prostaglandin E2 (PGE2) and anti-prostaglandin receptor 2 (EP2) antibodies were purchased from Abcam, Cambridge, MA, USA. OptEIA ELISA sets for mouse IFN $\gamma$, IL-10 and IL-4 were from BD Biosciences, San Jose, CA, USA. ODN 1585 CpG was purchased from InvivoGen, San Diego, CA, USA. Cell culture medium and Dulbecco's Phosphate-Buffered Saline (DPBS) were from CellGro Media Tech, Waltham, MA, USA. Fetal Calf Serum was purchased from Gibco, 
Life Technologies, Waltham, MA, USA. CD45 ${ }^{+}$cell purification system was purchased from Miltenyi Biotech, Bergisch Gladbach, Germany. Unless mentioned otherwise, all other reagents were from Sigma-Aldrich, Darmstadt, Germany. All kits for qPCR and kit for untouched T cells were purchased from Invitrogen, Waltham, MA, USA. Streptavidin-PE, anti-TLR4-APC, anti-MHC-II (IA/IE-AF647), CD86-AF488, CD83-PE, F4/80-BV421, goat anti-rat IgG-AF647 and goat anti-rat IgG-AF488 were purchased from Biolegend.

\subsection{Cell Lines and Animals}

ID8 represents a cell line derived from spontaneous malignant transformation of C57BL/6 mouse cells in vitro [57] and was a generous gift from Dr. Paul F. Terranova, University of Kansas, USA. Tumor cells were cultured in complete DMEM (Cellgro, New York, NY, USA) containing 10\% heat-inactivated fetal bovine serum (FBS, Life Technologies) and antibiotics (Penstrep (Gibco, Gaithersburg, MD, USA) at $10 \mathrm{U} / \mathrm{mL}$ culture medium and normocin, (Invitrogen, Waltham, MA, USA) at $0.1 \mathrm{mg} / \mathrm{mL}$ culture medium). Cells were regularly tested for mycoplasma. Specific pathogen-free grade 6-8 week-old female C57BL/6, OT-I (C57BL/6-Tg(TcraTcrb)1100Mjb/J) and OT-II (B6.CgTg(TcraTcrb)425Cbn/J) mice were purchased from the Jackson Laboratories, Sacramento, CA, USA. Animals were maintained according to the institutional guidelines. The research obtained ethical approval under the protocol \# 803648 provided by the Institutional Animal Care \& Use Committee of the University of Pennsylvania (IACUC).

\subsection{Preparation of Tumor Antigen}

Squaric acid-treated tumor lysates for antigen pulsing were prepared as previously reported [14]. Briefly, ID8 cells were resuspended at a concentration of $10^{8}$ cells $/ \mathrm{mL}$ in $0.06 \%$ squaric acid for $1 \mathrm{~h}$ at $37^{\circ} \mathrm{C}$ and subsequently lysed by 6 cycles of freeze and thaw, followed by sonication ( 5 watt output for $15 \mathrm{~s}, 3$ repeats on ice with $30 \mathrm{~s}$ intervals).

\subsection{Generation of Bone Marrow-Derived Mouse DCs}

DCs were generated from murine bone marrow cells, as described by Garrigan K. et al. [58] with minor modifications. Briefly, bone marrow was flushed from the long bones of ID8 tumor bearing mice. A single cell suspension was cultured in RPMI 1640 (CellGro, New York, NY, USA) supplemented with 10\% heat-inactivated FBS (Life Technologies, USA), 2 mM L-glutamine (Gibco, USA), $100 \mathrm{U} / \mathrm{mL}$ penicillin (Gibco, USA), $100 \mu \mathrm{g} / \mathrm{mL}$ streptomycin (Gibco, USA), $10 \mathrm{mM}$ HEPES pH 7.4 (Gibco, USA), $0.5 \mathrm{mM}$ sodium pyruvate (Cellgro, USA), 0.5\% MEM non-essential amino acids (Cellgro, USA), $0.1 \mathrm{mg} / \mathrm{mL}$ Normocin (InVivogen, San Diego, CA, USA). Cells were then differentiated according to (Figure 1) and as follows: For GM4 DCs -1 step or -2 step: with $20 \mathrm{ng} / \mathrm{mL}$ recombinant murine GM-CSF and $10 \mathrm{ng} / \mathrm{mL}$ IL-4 for 4 days (on day 2, the medium was replaced with fresh medium containing same cytokines); for GM15 1-step/2-step and DC5s: with $20 \mathrm{ng} / \mathrm{mL}$ GM-CSF and $10 \mathrm{ng} / \mathrm{mL}$ IL-15 for 4 days (on day 2, the medium was replaced with fresh medium containing same cytokines). For DC5 DCs: on day 1 with 20 ng/mL GM-CSF and 10 ng/mL IL-15; on day 2, the medium was replaced with fresh medium containing: GM-CSF $(20 \mathrm{ng} / \mathrm{mL}), \mathrm{IL}-15(10 \mathrm{ng} / \mathrm{mL})$ and both anti-PGE2 $(0.1 \mu \mathrm{g} / \mathrm{mL})$ and anti-EP2 $\mathrm{Ab}(0.2 \mu \mathrm{g} / \mathrm{mL})$. On day 4 , DCs were kept unpulsed or pulsed with squaric acid treated tumor lysate (LSQ) using $\sim 1$ tumor cell equivalent per DC and incubated for 12-16 h. After pulsing, DCs were matured as follows: for GM4-1 step and GM15-1 step: on day 5 the medium was removed and fresh medium containing $100 \mathrm{ng} / \mathrm{mL} \mathrm{LPS} \mathrm{and} 100 \mathrm{ng} / \mathrm{mL}$ IFN $\gamma$ was added and incubated for $24 \mathrm{~h}$ at $37{ }^{\circ} \mathrm{C}$ and $5 \% \mathrm{CO}_{2}$. For GM4-2 step and GM15-2 step: on day 4 fresh medium containing anti-CD40 Ab FGK45 $(0.2 \mu \mathrm{g} / \mathrm{mL})+$ anti-IL-10R blocking Ab $(0.5 \mu \mathrm{g} / \mathrm{mL})$ was added; on day 5 , the medium was removed and fresh medium containing LPS $(20 \mathrm{ng} / \mathrm{mL})$, IFN $\gamma$ (100 ng/mL) and CpG-ODN $1585(10 \mu \mathrm{g} / \mathrm{mL})$ was added and kept for $24 \mathrm{~h}$. For DC5 DCs: on day 4, fresh medium containing anti CD40 Ab FGK45 $(0.2 \mu \mathrm{g} / \mathrm{mL})+$ anti-IL-10R blocking Ab $(0.5 \mu \mathrm{g} / \mathrm{mL})+$ anti-EP2 $\mathrm{Ab}(0.1 \mu \mathrm{g} / \mathrm{mL})+$ anti-PGE2 $(0.1 \mu \mathrm{g} / \mathrm{mL})$ was added. After $3 \mathrm{~h}$, the medium was removed 
and fresh medium containing anti-PGE2 $(0.1 \mu \mathrm{g} / \mathrm{mL})$, anti-EP2 Ab $(0.2 \mu \mathrm{g} / \mathrm{mL})$, LPS $(20 \mathrm{ng} / \mathrm{mL})$, IFN $\gamma(100 \mathrm{ng} / \mathrm{mL})$ and CpG-ODN $1585(10 \mu \mathrm{g} / \mathrm{mL})$ was added and incubated overnight. Cells were then harvested, stained with indicated antibodies followed by FACS analysis (Canto-II, BD bioscience, San Jose, CA, USA) or used for animal vaccination.

\subsection{Vaccination}

$1 \times 10^{6}$ DCs (resuspended in $500 \mu \mathrm{L}$ DPBS) were injected i.p. on day 7, 14 and 21 following intraperitoneal inoculation of $1 \times 10^{6}$ ID8 cells (in $500 \mu \mathrm{L}$ DPBS) at day 0 . Animals were monitored regularly for tumor growth by measuring the body weight. Mice attaining $30 \mathrm{~g}$ body weight were sacrificed ( $40 \%$ increase in body weight over age/sex-matched normal mice).

\subsection{Adoptive T Cell Transfer Experiments}

ID8 tumor-bearing female C57BL/6 mice were vaccinated as reported above. Lymph node (LN) cells were then collected from inguinal LN on day 28 post tumor inoculation and $\mathrm{T}$ cells isolated by negative selection with the dynabeads mouse T cell kit (Thermofisher, Waltham, MA, USA), following manufacturer instructions. $1 \times 10^{6} \mathrm{~T}$ cells were then injected in the tail vein of each recipient mice 3 days before tumor challenge with i.p. injection of ID8 cells $\left(1 \times 10^{6} /\right.$ animal $)$. Animals were monitored regularly for tumor growth. Mice attaining $30 \mathrm{~g}$ body weight were sacrificed ( 40\% increase in body weight over age/sex-matched normal mice).

\subsection{DC and T Cell Co-Culture}

T cells from spleen or draining lymph nodes (mesenteric and inguinal) or ascites or peritoneal exudate of normal and tumor bearing (ID8) animals (receiving 3 consecutive injections of placebo (PBS) or DC vaccine on day 7,14 and 21 post tumor inoculation) were purified using negative selection kit (Invitrogen, USA). $1 \times 10^{5}$ T cells were plated with $1 \times 10^{4} \mathrm{DCs}$ and cultured for $96 \mathrm{~h}$ in a culture volume of $200 \mu \mathrm{L}$. When indicated, the culture was treated with $5 \mathrm{ng} / \mathrm{mL}$ recombinant mouse IL-12 (Peprotech, USA). Cells were incubated with Brefeldin A (final concentration $2 \mu \mathrm{g} / \mathrm{mL}$ ) for $8 \mathrm{~h}$ and then harvested. Cells were then stained with indicated antibodies followed by FACS analysis (Canto-II, BD Biosciences) or analyzed by RTqPCR. Cell-free culture supernatants were also taken to measure levels of indicated cytokines by ELISA (OptEIA, BD Biosciences, USA) according to manufacturer procedures.

\subsection{Reverse Transcription-Quantitative Polymerase Chain Reaction (RTqPCR)}

RTqPCR was carried out using oligo-dT primer and Superscript-III reverse transcriptase (Thermo Fisher, USA). Real time PCR was performed with standard primer-probe sets obtained from Thermo Fisher, USA, following manufacturer instructions.

\subsection{Statistical Analysis}

SAS software (Version 9.3, SAS, Cary, NC, USA) and StatXact Procs 9 (Cytel, Cambridge, MA, USA) for SAS were used for statistical analysis. In particular, a two-tailed Student's $t$-test was used to compare means of continuous measurements between two groups. The analysis of variance (ANOVA) was used to compare means among more than two groups; differences were considered statistically significant when $p<0.05$. For animal survival, statistical analysis was performed with GraphPad Prism software using Log-rank (Mantel-Cox) test.

\section{Conclusions}

In this work, through a stepwise approach we describe a novel formulation for a DC cancer vaccine with both in vitro an in vivo improved efficacy in a mouse model, compared to canonical DC vaccine preparations that were previously available and largely in use in the field. The encouraging results here presented in the context of ovarian cancer also support future work aimed at translating 
this approach in the clinic, especially in combination with other adjuvant immunotherapy (such as checkpoint blockades) to further improve therapeutic outcomes.

Supplementary Materials: The following are available online at http:/ /www.mdpi.com/2072-6694/11/1/40/s1, Figure S1: Example of the gating strategy for DCs and for the surface marker CD86, Figure S2: DCs matured with a two-step protocol in the presence of anti-CD40 and anti-IL10R antibodies for $24 \mathrm{~h}$, followed by LPS/IFN $\gamma / \mathrm{CpG}$ stimulate a more Th1-skewed T cell response compared to canonical LPS/IFN $\gamma$ maturation.

Author Contributions: A.M. performed experiments and data collection; A.M. and M.G. analyzed data; A.M., M.G. and L.E.K. wrote the manuscript; L.E.K. designed and supervised the study.

Funding: This research was funded by the Marcus Foundation, grant number 558505.

Acknowledgments: We wish to thank George Coukos for useful discussions and for his critical review of the manuscript.

Conflicts of Interest: The authors declare no conflict of interest. The funders had no role in the design of the study; in the collection, analyses, or interpretation of data; in the writing of the manuscript, or in the decision to publish the results.

\section{References}

1. Ferlay, J.; Shin, H.-R.; Bray, F.; Forman, D.; Mathers, C.; Parkin, D.M. Estimates of worldwide burden of cancer in 2008: GLOBOCAN 2008. Int. J. Cancer 2010, 127, 2893-2917. [CrossRef] [PubMed]

2. Alexandrov, L.B.; Nik-Zainal, S.; Wedge, D.C.; Aparicio, S.A.J.R.; Behjati, S.; Biankin, A.V.; Bignell, G.R.; Bolli, N.; Borg, A.; Børresen-Dale, A.L.; et al. Signatures of mutational processes in human cancer. Nature 2013, 500, 415-421. [CrossRef] [PubMed]

3. Chalmers, Z.R.; Connelly, C.F.; Fabrizio, D.; Gay, L.; Ali, S.M.; Ennis, R.; Schrock, A.; Campbell, B.; Shlien, A.; Chmielecki, J.; et al. Analysis of 100,000 human cancer genomes reveals the landscape of tumor mutational burden. Genome Med. 2017, 9, 34. [CrossRef] [PubMed]

4. Zhang, L.; Conejo-Garcia, J.R.; Katsaros, D.; Gimotty, P.A.; Massobrio, M.; Regnani, G.; Makrigiannakis, A.; Gray, H.; Schlienger, K.; Liebman, M.N.; et al. Intratumoral T Cells, Recurrence, and Survival in Epithelial Ovarian Cancer. N. Engl. J. Med. 2003, 348, 203-213. [CrossRef] [PubMed]

5. Santin, A.D.; Hermonat, P.L.; Ravaggi, A.; Bellone, S.; Roman, J.J.; Smith, C.V.; Pecorelli, S.; Radominska-Pandya, A.; Cannon, M.J.; Parham, G.P. Phenotypic and Functional Analysis of Tumor-Infiltrating Lymphocytes Compared with Tumor-Associated Lymphocytes from Ascitic Fluid and Peripheral Blood Lymphocytes in Patients with Advanced Ovarian Cancer. Gynecol. Obstet. Investig. 2001, 51, 254-261. [CrossRef] [PubMed]

6. Martin Lluesma, S.; Wolfer, A.; Harari, A.; Kandalaft, L. Cancer Vaccines in Ovarian Cancer: How Can We Improve? Biomedicines 2016, 4, 10. [CrossRef]

7. Schaaf, M.; Garg, A.D.; Perez, M.V.; Schaaf, M.; Agostinis, P. Trial Watch: Dendritic cell-based anticancer immunotherapy Trial Watch: Dendritic cell-based anticancer immunotherapy. Oncoimmunology 2017, 2, e1328341. [CrossRef]

8. Banchereau, J.; Briere, F.; Caux, C.; Davoust, J.; Lebecque, S.; Liu, Y.J.; Pulendran, B.; Palucka, K. Immunobiology of dendritic cells. Annu. Rev. Immunol. 2000, 18, 767-811. [CrossRef]

9. Garg, A.D.; Coulie, P.G.; Van den Eynde, B.J.; Agostinis, P. Integrating Next-Generation Dendritic Cell Vaccines into the Current Cancer Immunotherapy Landscape. Trends Immunol. 2017, 38, 577-593. [CrossRef]

10. Bol, K.F.; Schreibelt, G.; Gerritsen, W.R.; De Vries, I.J.M.; Figdor, C.G. Dendritic cell-based immunotherapy: State of the art and beyond. Clin. Cancer Res. 2016, 22, 1897-1906. [CrossRef]

11. Saxena, M.; Bhardwaj, N. Re-Emergence of Dendritic Cell Vaccines for Cancer Treatment. Trends Cancer 2018, 4, 119-137. [CrossRef] [PubMed]

12. Chiang, C.L.L.; Kandalaft, L.E.; Tanyi, J.; Hagemann, A.R.; Motz, G.T.; Svoronos, N.; Montone, K.; Mantia-Smaldone, G.M.; Smith, L.; Nisenbaum, H.L.; et al. A dendritic cell vaccine pulsed with autologous hypochlorous acid-oxidized ovarian cancer lysate primes effective broad antitumor immunity: From bench to bedside. Clin. Cancer Res. 2013, 19, 4801-4815. [CrossRef] [PubMed]

13. Kandalaft, L.E.; Chiang, C.L.; Tanyi, J.; Motz, G.; Balint, K.; Mick, R.; Coukos, G. A Phase I vaccine trial using dendritic cells pulsed with autologous oxidized lysate for recurrent ovarian cancer. J. Transl. Med. 2013, 11, 149. [CrossRef] [PubMed] 
14. Mookerjee, A.; Graciotti, M.; Kandalaft, L. A cancer vaccine with dendritic cells differentiated with GM-CSF and IFNa and pulsed with a squaric acid treated cell lysate improves $\mathrm{T}$ cell priming and tumor growth control in a mouse model. BioImpacts 2018, 8, 211-221. [CrossRef]

15. Anguille, S.; Smits, E.L.; Bryant, C.; Van Acker, H.H.; Goossens, H.; Lion, E.; Fromm, P.D.; Van Tendeloo, V.F.; Berneman, Z.N. Dendritic Cells as Pharmacological Tools for Cancer Immunotherapy. Pharmacol. Rev. 2015, 67, 731-753. [CrossRef] [PubMed]

16. Anguille, S.; Lion, E.; Van Den Bergh, J.; Van Acker, H.H.; Willemen, Y.; Smits, E.L.; Van Tendeloo, V.F.; Berneman, Z.N. Interleukin-15 dendritic cells as vaccine candidates for cancer immunotherapy. Hum. Vaccines Immunother. 2013, 9, 1956-1961. [CrossRef]

17. Harris, K.M. Monocytes differentiated with GM-CSF and IL-15 initiate Th17 and Th1 responses that are contact-dependent and mediated by IL-15. J. Leukoc. Biol. 2011, 90, 727-734. [CrossRef] [PubMed]

18. Pulendran, B.; Dillon, S.; Joseph, C.; Curiel, T.; Banchereau, J.; Mohamadzadeh, M. Dendritic cells generated in the presence of GM-CSF plus IL-15 prime potent CD8+ Tc1 responses in vivo. Eur. J. Immunol. 2004, 34, 66-73. [CrossRef] [PubMed]

19. Lee, A.W.; Truong, T.; Bickham, K.; Fonteneau, J.F.; Larsson, M.; Da Silva, I.; Somersan, S.; Thomas, E.K.; Bhardwaj, N. A clinical grade cocktail of cytokines and PGE2 results in uniform maturation of human monocyte-derived dendritic cells: Implications for immunotherapy. Vaccine 2002, 20, 8-22. [CrossRef]

20. Martin Lluesma, S.; Graciotti, M.; Chiang, C.; Kandalaft, L. Does the Immunocompetent Status of Cancer Patients Have an Impact on Therapeutic DC Vaccination Strategies? Vaccines 2018, 6, 79. [CrossRef]

21. Lasek, W.; Zagożdżon, R.; Jakobisiak, M. Interleukin 12: Still a promising candidate for tumor immunotherapy? Cancer Immunol. Immunother. 2014, 63, 419-435. [CrossRef] [PubMed]

22. Chiang, C.L.-L.; Maier, D.A.; Kandalaft, L.E.; Brennan, A.L.; Lanitis, E.; Ye, Q.; Levine, B.L.; Czerniecki, B.J.; Powell, D.J., Jr.; Coukos, G. Optimizing parameters for clinical-scale production of high IL-12 secreting dendritic cells pulsed with oxidized whole tumor cell lysate. J. Transl. Med. 2011, 9, 198. [CrossRef]

23. Chiang, C.L.L.; Hagemann, A.R.; Leskowitz, R.; Mick, R.; Garrabrant, T.; Czerniecki, B.J.; Kandalaft, L.E.; Powell, D.J.; Coukos, G. Day-4 myeloid dendritic cells pulsed with whole tumor lysate are highly immunogenic and elicit potent anti-tumor responses. PLOS ONE 2011, 6. [CrossRef] [PubMed]

24. Tanyi, J.L.; Bobisse, S.; Ophir, E.; Tuyaerts, S.; Roberti, A.; Genolet, R.; Baumgartner, P.; Stevenson, B.J.; Iseli, C.; Dangaj, D.; et al. Personalized cancer vaccine effectively mobilizes antitumor T cell immunity in ovarian cancer. Sci. Transl. Med. 2018, 10, eaao5931. [CrossRef]

25. Carreno, B.M.; Becker-Hapak, M.; Huang, A.; Chan, M.; Alyasiry, A.; Lie, W.R.; Aft, R.L.; Cornelius, L.A.; Trinkaus, K.M.; Linette, G.P. IL-12p70-producing patient DC vaccine elicits Tc1-polarized immunity. J. Clin. Investig. 2013, 123, 3383-3394. [CrossRef]

26. Lee, J.-J.; Foon, K.A.; Mailliard, R.B.; Muthuswamy, R.; Kalinski, P. Type 1-polarized dendritic cells loaded with autologous tumor are a potent immunogen against chronic lymphocytic leukemia. J. Leukoc. Biol. 2008, 84, 319-325. [CrossRef] [PubMed]

27. Anguille, S.; Smits, E.L.J.M.; Cools, N.; Goossens, H.; Berneman, Z.N.; Van Tendeloo, V.F.I. Short-term cultured, interleukin-15 differentiated dendritic cells have potent immunostimulatory properties. J. Transl. Med. 2009, 7, 109. [CrossRef] [PubMed]

28. Hira, S.K.; Mondal, I.; Manna, P.P. Combined immunotherapy with whole tumor lysate-pulsed interleukin-15-activated dendritic cells and cucurbitacin I promotes strong CD8+ T-cell responses and cures highly aggressive lymphoma. Cytotherapy 2015, 17, 647-664. [CrossRef]

29. Van Acker, H.H.; Beretta, O.; Anguille, S.; De Caluwé, L.; Papagna, A.; Van den Bergh, J.M.; Willemen, Y.; Goossens, H.; Berneman, Z.N.; Van Tendeloo, V.F.; et al. Desirable cytolytic immune effector cell recruitment by interleukin-15 dendritic cells. Oncotarget 2017, 8, 13652-13665. [CrossRef]

30. Würtzen, P.A.; Nissen, M.H.; Claesson, M.H. Maturation of dendritic cells by recombinant human CD40L-trimer leads to a homogeneous cell population with enhanced surface marker expression and increased cytokine production. Scand. J. Immunol. 2001, 53, 579-587. [CrossRef]

31. Brunekreeft, K.L.; Strohm, C.; Gooden, M.J.; Rybczynska, A.A.; Nijman, H.W.; Grigoleit, G.U.; Helfrich, W.; Bremer, E.; Siegmund, D.; Wajant, H.; et al. Targeted delivery of CD40L promotes restricted activation of antigen-presenting cells and induction of cancer cell death. Mol. Cancer 2014, 13, 85. [CrossRef] [PubMed] 
32. Guo, Z.; Gao, H.-Y.; Zhang, T.-Y.; Lou, J.-X.; Yang, K.; Liu, X.-D.; He, X.-P.; Chen, H.-R. Adenovirus co-expressing CD40 ligand and interleukin (IL)-2 contributes to maturation of dendritic cells and production of IL-12. Biomed. Rep. 2016, 5, 567-573. [CrossRef] [PubMed]

33. Corinti, S.; Albanesi, C.; la Sala, A.; Pastore, S.; Girolomoni, G. Regulatory Activity of Autocrine IL-10 on Dendritic Cell Functions. J. Immunol. 2001, 166, 4312-4318. [CrossRef]

34. Manuzak, J.; Dillon, S.; Wilson, C. Differential interleukin-10 (IL-10) and IL-23 production by human blood monocytes and dendritic cells in response to commensal enteric bacteria. Clin. Vaccine Immunol. 2012, 19, 1207-1217. [CrossRef]

35. Murad, Y.M.; Clay, T.M. CpG oligodeoxynucleotides as TLR9 agonists: Therapeutic applications in cancer. BioDrugs 2009, 23, 361-375. [CrossRef] [PubMed]

36. Kaliński, P.; Hilkens, C.M.; Snijders, A.; Snijdewint, F.G.; Kapsenberg, M.L. IL-12-deficient dendritic cells, generated in the presence of prostaglandin E2, promote type 2 cytokine production in maturing human naive T helper cells. J. Immunol. 1997, 159, 28-35. [PubMed]

37. Sharma, S.; Stolina, M.; Yang, S.-C.; Baratelli, F.; Lin, J.F.; Atianzar, K.; Luo, J.; Zhu, L.; Lin, Y.; Huang, M.; et al. Tumor cyclooxygenase 2-dependent suppression of dendritic cell function. Clin. Cancer Res. 2003, 9, 961-968. [PubMed]

38. Obermajer, N.; Muthuswamy, R.; Lesnock, J.; Edwards, R.P.; Kalinski, P. Positive feedback between PGE2 and COX2 redirects the differentiation of human dendritic cells toward stable myeloid-derived suppressor cells. Blood 2011, 118, 5498-5505. [CrossRef]

39. Mohamadzadeh, M.; Berard, F.; Essert, G.; Chalouni, C.; Pulendran, B.; Davoust, J.; Bridges, G.; Palucka, A.K.; Banchereau, J. Interleukin 15 skews monocyte differentiation into dendritic cells with features of Langerhans cells. J. Exp. Med. 2001, 194, 1013-1020. [CrossRef]

40. Dubsky, P.; Saito, H.; Leogier, M.; Dantin, C.; Connolly, J.E.; Banchereau, J.; Palucka, A.K. IL-15-induced human DC efficiently prime melanomaspecific naive CD8+T cells to differentiate into CTL. Eur. J. Immunol. 2007, 37, 1678-1690. [CrossRef]

41. Romano, E.; Rossi, M.; Ratzinger, G.; De Cos, M.A.; Chung, D.J.; Panageas, K.S.; Wolchock, J.D.; Houghton, A.N.; Chapman, P.B.; Heller, G.; et al. Peptide-loaded langerhans cells, despite increased IL15 secretion and T-cell activation in vitro, elicit antitumor T-cell responses comparable to peptide-loaded monocyte-derived dendritic cells in vivo. Clin. Cancer Res. 2011, 17, 1984-1997. [CrossRef] [PubMed]

42. Ahmed, S.; Bae, Y.-S. Dendritic cell-based therapeutic cancer vaccines: Past, present and future. Clin. Exp. Vaccine Res. 2014, 3, 113-116. [CrossRef]

43. Anguille, S.; Smits, E.L.; Lion, E.; Van Tendeloo, V.F.; Berneman, Z.N. Clinical use of dendritic cells for cancer therapy. Lancet Oncol. 2014, 15, e257-e267. [CrossRef]

44. Heath, W.R.; Carbone, F.R. Cross-presentation in viral immunity and self-tolerance. Nat. Rev. Immunol. 2001, 1, 126-134. [CrossRef] [PubMed]

45. Frleta, D.; Noelle, R.J.; Wade, W.F. CD40-mediated up-regulation of Toll-like receptor 4-MD2 complex on the surface of murine dendritic cells. J. Leukoc. Biol. 2003, 74, 1064-1073. [CrossRef] [PubMed]

46. Worzfeld, T.; Pogge von Strandmann, E.; Huber, M.; Adhikary, T.; Wagner, U.; Reinartz, S.; Müller, R. The Unique Molecular and Cellular Microenvironment of Ovarian Cancer. Front. Oncol. 2017, 7, 24. [CrossRef] [PubMed]

47. Ghoneum, A.; Afify, H.; Salih, Z.; Kelly, M.; Said, N. Role of tumor microenvironment in ovarian cancer pathobiology. Oncotarget 2018, 9, 22832-22849. [CrossRef]

48. Bronger, H.; Singer, J.; Windmüller, C.; Reuning, U.; Zech, D.; Delbridge, C.; Dorn, J.; Kiechle, M.; Schmalfeldt, B.; Schmitt, M.; et al. CXCL9 and CXCL10 predict survival and are regulated by cyclooxygenase inhibition in advanced serous ovarian cancer. Br. J. Cancer 2016, 115, 553-563. [CrossRef]

49. Liu, M.; Matsumura, N.; Mandai, M.; Li, K.; Yagi, H.; Baba, T.; Suzuki, A.; Hamanishi, J.; Fukuhara, K.; Konishi, I. Classification using hierarchical clustering of tumor-infiltrating immune cells identifies poor prognostic ovarian cancers with high levels of COX expression. Mod. Pathol. 2009, 22, 373-384. [CrossRef]

50. Walker, C.; Kristensen, F.; Bettens, F.; deWeck, A.L. Lymphokine regulation of activated (G1) lymphocytes. I. Prostaglandin E2-induced inhibition of interleukin 2 production. J. Immunol. 1983, 130, 1770-1773.

51. Kalinski, P. Regulation of Immune Responses by Prostaglandin E2. J. Immunol. 2012, 188, 21-28. [CrossRef] [PubMed] 
52. Harizi, H.; Grosset, C.; Gualde, N. Prostaglandin E2 modulates dendritic cell function via EP2 and EP4 receptor subtypes. J. Leukoc. Biol. 2003, 73, 756-763. [CrossRef] [PubMed]

53. Legitimo, A.; Consolini, R.; Failli, A.; Orsini, G.; Spisni, R. Dendritic cell defects in the colorectal cancer. Hum. Vaccines Immunother. 2014, 10, 3224-3235. [CrossRef] [PubMed]

54. Gabrilovich, D.I.; Corak, J.; Ciernik, I.F.; Kavanaugh, D.Y.; Carbone, D.P. Decreased antigen presentation by dendritic cells in patients with breast cancer. Clin. Cancer Res. 1997, 3, 483-490. [PubMed]

55. Takahashi, K.; Toyokawa, H.; Takai, S.; Satoi, S.; Yanagimoto, H.; Terakawa, N.; Araki, H.; Kwon, A.H.; Kamiyama, Y. Surgical influence of pancreatectomy on the function and count of circulating dendritic cells in patients with pancreatic cancer. Cancer Immunol. Immunother. 2006, 55, 775-784. [CrossRef] [PubMed]

56. Della Porta, M.; Danova, M.; Rigolin, G.M.; Brugnatelli, S.; Rovati, B.; Tronconi, C.; Fraulini, C.; Rossi, A.R.; Riccardi, A.; Castoldi, G. Dendritic cells and vascular endothelial growth factor in colorectal cancer: Correlations with clinicobiological findings. Oncology 2005, 68, 276-284. [CrossRef]

57. Roby, K.F.; Taylor, C.C.; Sweetwood, J.P.; Cheng, Y.; Pace, J.L.; Tawfik, O.; Persons, D.L.; Smith, P.G.; Terranova, P.F. Development of a syngeneic mouse model for events related to ovarian cancer. Carcinogenesis 2000, 21, 585-591. [CrossRef]

58. Garrigan, K.; Moroni-Rawson, P.; McMurray, C.; Hermans, I.; Abernethy, N.; Watson, J.; Ronchese, F. Functional comparison of spleen dendritic cells and dendritic cells cultured in vitro from bone marrow precursors. Blood 1996, 88, 3508-3512.

(C) 2019 by the authors. Licensee MDPI, Basel, Switzerland. This article is an open access article distributed under the terms and conditions of the Creative Commons Attribution (CC BY) license (http:/ / creativecommons.org/licenses/by/4.0/). 